\title{
Prospective study on diagnostic and prognostic significance of postoperative FDG PET/CT in recurrent colorectal carcinoma patients: comparison with MRI and tumor markers
}

\author{
S. ODALOVIC ${ }^{1,2, *}$, M. STOJILJKOVIC ${ }^{1}$, D. SOBIC-SARANOVIC ${ }^{1,2}$, S. PANDUREVIC ${ }^{2}$, L. BRAJKOVIC ${ }^{1}$, I. MILOSEVIC ${ }^{1}$, I. GROZDIC-MILOJEVIC ${ }^{1}$, \\ V. ARTIKO 1,2
}

${ }^{1}$ Center of Nuclear Medicine, Clinical Center of Serbia, Belgrade, Serbia; ${ }^{2}$ Faculty of Medicine, University of Belgrade, Belgrade, Serbia

${ }^{*}$ Correspondence: cale_odl@yahoo.com

Received November 10, 2016 / Accepted May 3, 2017

\begin{abstract}
Current guidelines for follow-up after resection of colorectal cancer (CRC) recommend regular measurements of carcinoembryogenic antigen (CEA) and imaging tests. Multidetector computed tomography (MDCT) and magnetic resonance imaging (MRI) are currently primary imaging modalities, while the role of fluorine-18-fluoro-deoxyglucose positron emission tomography/computed tomography $\left({ }^{18} \mathrm{~F}-\mathrm{FDG} \mathrm{PET} / \mathrm{CT}\right)$, which is recommended in patients with negative MDCT and increased CEA, is still uncertain. Our aim was to compare diagnostic performance and prognostic significance of ${ }^{18} \mathrm{~F}-\mathrm{FDG}$ PET/CT with MRI and tumor markers CEA and carbohydrate antigen 19-9 (CA 19-9) in detection of recurrent CRC. This prospective study included 35 patients with resected CRC, referred to ${ }^{18} \mathrm{~F}-\mathrm{FDG}$ PET/CT examination for suspected recurrence. During median follow-up of $24.4 \pm 1.5$ months ${ }^{18} \mathrm{~F}-\mathrm{FDG}$ PET/CT and MRI results and tumor marker levels were compared with findings of histopathological examination or with results of clinical and imaging follow-up. Management plan before the ${ }^{18} \mathrm{~F}-\mathrm{FDG}$ PET/CT scan was considered and compared to the final treatment decision. The sensitivity, specificity, positive and negative predictive value and accuracy of ${ }^{18} \mathrm{~F}$-FDG PET/CT and MRI in detection of recurrent colorectal cancer in patient-based analysis were $92.6 \%, 75 \%, 92.6 \%, 75 \%$ and $88.6 \%$, and $65.4 \%, 66.7 \%, 85 \%, 40 \%$ and $65.7 \%$, respectively. In lesion-based analysis the sensitivity of ${ }^{18} \mathrm{~F}-\mathrm{FDG}$ PET/CT and MRI was $83.1 \%$ and $68.2 \%$, respectively. The overall accuracy of CEA and CA $19-9$ in recurrence detection was $48.6 \%$ and $54.3 \%$, respectively. PET/CT induced therapy alterations in $13 / 35$ (37.1\%) patients. Progression was observed in 16/35 patients during follow-up, with significantly lower risk of progression in patients with treatment changes based on PET findings (Multivariate Cox regression; $p=0.017$ ). In addition, elevated CA 19-9 levels in time of PET scan and male gender carried significantly higher risk of progression ( $\mathrm{p}=0.007$ and $\mathrm{p}=0.016$, respectively). Kaplan-Meier Log rank test showed significantly longer progression-free survival time in patients who had treatment plan changed based on PET/CT ( $\mathrm{p}=0.046)$. We can conclude that ${ }^{18} \mathrm{~F}-\mathrm{FDG}$ PET/CT showed better sensitivity and accuracy compared to MRI in detection of recurrent colorectal cancer, with much better sensitivity compared to CEA and CA 19-9. Patients with treatment changes based on ${ }^{18} \mathrm{~F}-\mathrm{FDG}$ PET/CT had significantly better prognosis and longer progression-free survival, while elevated values of CA 19-9 and male gender were associated with worse prognosis.
\end{abstract}

Key words: FDG PET/CT, colorectal cancer, magnetic resonance imaging, tumor markers, prognosis

Colorectal cancer (CRC) is third among all types of cancer based on incidence and mortality, in males and females both [1]. Although mortality is decreasing by about $3 \%$ per annum, changes in risk factors and screening measures account for $88 \%$ of the improvement, while advances in therapy are responsible for mere $12 \%$ [2]. One of the reasons for such response could be the high frequency of relapses after seemingly curative procedures [3].
Current guidelines for managing patients with CRC after therapy recommend regular measurements of serum carcinoembryogenic antigen (CEA) and imaging tests [4]. CEA, although sensitive in detecting early relapse, gives very often a false-positive result [5]. The role of carbohydrate antigen 19-9 (CA 19-9) in detection of recurrent CRC is still unclear, although there have been studies suggesting its potential prognostic significance [6]. In addition, increased CEA and CA 
19-9 values require localization of recurrent disease, which is done with imaging studies [7]. For diagnosis and follow-up of $\mathrm{CRC}$, following modalities are used: multidetector computed tomography (MDCT), magnetic resonance imaging (MRI), and fluorine-18-fluoro-deoxyglucose positron emission tomography/computed tomography $\left({ }^{18} \mathrm{~F}-\mathrm{FDG}\right.$ PET/CT). MDCT and MRI are currently primary imaging modalities, by which the progression of colorectal carcinoma is established, while ${ }^{18} \mathrm{~F}-\mathrm{FDG} \mathrm{PET} / \mathrm{CT}$ is recommended in patients with negative MDCT and otherwise unexplained CEA increase [4]. In contrast to MDCT and MRI, which use anatomic parameters (lesion size) to evaluate therapy outcome, ${ }^{18} \mathrm{~F}-\mathrm{FDG}$ PET/CT quantifies functional change, a better predictor to disease development according to some authors [8].

Nevertheless, the status of ${ }^{18} \mathrm{~F}-\mathrm{FDG}$ PET/CT in evaluation of therapy response in colorectal carcinoma, among other imaging modalities, as well as in different phases of disease, is still uncertain $[8,9,10]$. Moreover, there is an unsatisfied need for determining the optimal sequence in utilizing different imaging modalities on suspicion of metastasis, in effort to avoid unnecessary interventions, increase the effect of therapy and raise the survival rate [4].

The aim of this prospective study was to compare diagnostic performance of imaging tools $\left({ }^{18} \mathrm{~F}-\mathrm{FDG}\right.$ PET/CT and MRI) and biochemical markers (CEA and CA 19-9) in detection recurrent colorectal cancer in clinical practice, with emphasis on impact of ${ }^{18} \mathrm{~F}-\mathrm{FDG}$ PET/CT on further treatment. The second aim was to assess prognostic significance of imaging and biochemical tests for progression-free survival in recurrent colorectal cancer.

\section{Patients and methods}

Study population. This prospective study included consecutive patients with resected colorectal adenocarcinoma referred to ${ }^{18} \mathrm{~F}-\mathrm{FDG}$ PET/CT examination at National PET Center, Clinical Center of Serbia, Belgrade, from May 2011 to February 2015. The inclusion criteria were: resected colorectal adenocarcinoma and period of at least 6 months after resection, MR imaging of abdomen and pelvis one month prior to PET/CT, follow-up of at least 24 months and glucose level not greater than $11.0 \mathrm{mmol} / \mathrm{l}$. The exclusion criteria included pregnancy and the presence or history of another type of malignancy. The final sample consisted of 35 patients ( 14 females and 21 males, mean age $60.6 \pm 10.6$ years).

Procedures. The ${ }^{18} \mathrm{~F}-\mathrm{FDG}$ PET/CT examination was performed when patients had symptoms and signs suggesting loco-regional recurrence or liver metastases, abnormal or equivocal contrast-enhanced MDCT and/or elevated tumor marker levels. One month prior to ${ }^{18} \mathrm{~F}-\mathrm{FDG}$ PET/CT all patients underwent MRI imaging and measurements of serum levels of CEA and CA 19-9. During 24 months of follow-up clinical data, results of imaging tests and laboratory data were collected and evaluated. Findings of ${ }^{18} \mathrm{~F}-\mathrm{FDG}$ PET/CT and MRI were compared with findings of histopathological examination or with results of subsequent clinical and imaging follow-up. Management plan before the ${ }^{18} \mathrm{~F}-\mathrm{FDG}$ PET/CT scan was considered and compared to the final decision for treatment after the PET/CT scan. The primary end-point was progression-free survival, based on imaging findings, clinical examination and/or cancer related death. After PET/CT examination, patients were followed for at least 24 months, with a mean follow-up time of $24.4 \pm 1.5$ (range 24-32 months). The study was approved by the Ethics Committee of the Faculty of Medicine of the University of Belgrade and written consent was obtained.

Data acquisition and interpretation. The patients underwent ${ }^{18} \mathrm{~F}$-FDG PET/CT examination on a 64-slice hybrid PET/ CT scanner (Biograph, TruePoint64, Siemens Medical Solutions, Inc. USA) at National PET Center, Clinical Center of Serbia, Belgrade. After fasting for $6 \mathrm{~h}$ patients received an intravenous injection of $5.5 \mathrm{MBq} / \mathrm{kg}$ of ${ }^{18} \mathrm{~F}-\mathrm{FDG}$. Following injection of ${ }^{18} \mathrm{~F}-\mathrm{FDG}$, patients rested in a quiet and darkened room for $60 \mathrm{~min}$, after which images of PET/CT were obtained. Low-dose non-enhanced CT scans $(120 \mathrm{kV}$ with automatic, real-time dosemodulation amperage, slice thickness of $5 \mathrm{~mm}$, pitch of 1,5 and a rotation time of $0.5 \mathrm{~s}$ ) and 3-dimensional PET scans (6-7 fields of view, $3 \mathrm{~min} /$ field) were acquired from the base of the skull to the mid-thigh. Non-corrected and attenuation-corrected CT, PET and fused PET/CT images were displayed for analysis on a Syngo Multimodality workplace (Siemens AG).

Any lesion with high ${ }^{18} \mathrm{~F}$-FDG uptake on PET/CT was defined as positive for malignancy if any abnormal ${ }^{18} \mathrm{~F}-\mathrm{FDG}$ uptake was observed after exclusion of benign and physiological lesions, with or without clearly visible corresponding CT malformation. Lesions were analyzed qualitatively and semi-quantitatively. For assessment of glucose metabolism level in metastasis, SUVmax was used, that is singular voxel within volume of interest with maximal standard uptake value, calculated as: activity in tissue (count/pixel/s) multiplied by calibration factor and divided by dose applied (MBq/kg of body weight). Tumor lesions were defined by volume of interest (VOI) placed around every suspected focus of intense FDG uptake, with 50\% threshold. The measurements of SUVmax, were done on reconstructed images, after using ordered subsets expectation maximization (OSEM) as statistical reconstruction method, but no absolute cut-off value of SUVmax was used for the diagnosis. Images were interpreted separately by two nuclear medicine physicians, unaware of results of other imaging modalities. In cases of discrepancy, images were presented to multidisciplinary team and experts' opinion was adopted.

PET/CT findings were compared to MR imaging findings. T1 weighted, T2wieghted, diffusion-weighted images (DWI), as well as contrast enhanced images of abdomen, pelvis and basal lungs were acquired in all patients, and were interpreted by experienced radiologists, unaware of PET/CT results. Characterization of lesions was based on standard evaluation criteria by visual characteristics, and all lesions were classified as malignant, benign or equivocal. Equivocal lesions were considered as false-positives or false-negatives after comparison with the gold standard. 

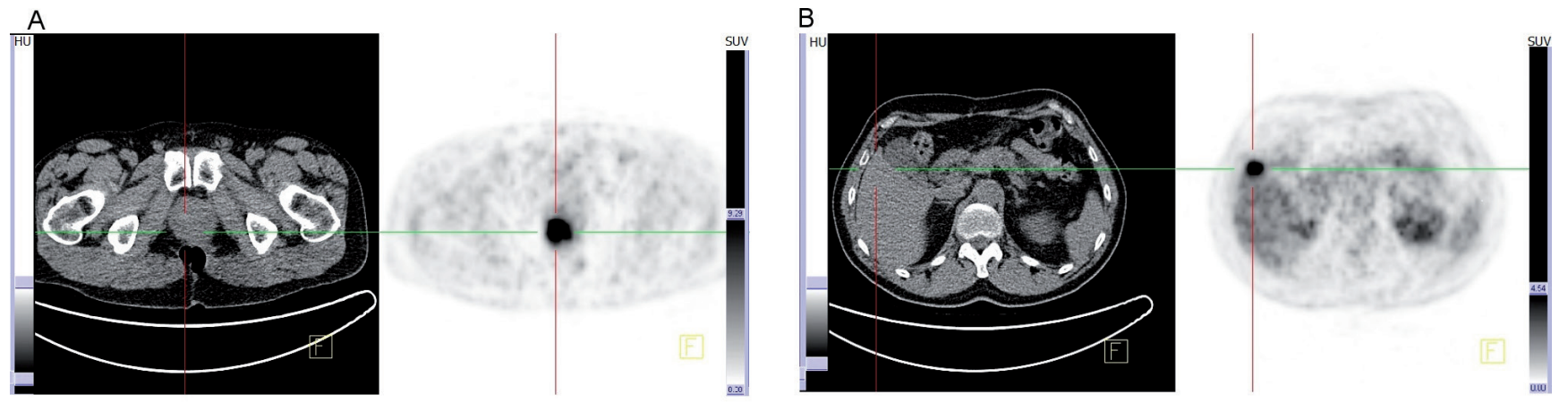

Figure 1. (A) CT and PET image showing local recurrence of rectal cancer in 55 year-old male patient (CEA 6 ng/ml; CA 19-9 97 U/ml); (B) CT and PET image of liver metastasis of CRC in 57 year-old male patient with elevated CEA $(50 \mathrm{ng} / \mathrm{ml})$ and normal CA 19-9

Final diagnosis of recurrent disease was made either by histopathological examination, or imaging follow-up during first six months after PET/CT. Histopathological confirmation was obtained in 14 patients, out of who in 10 patients verification came after surgical treatment, while in 4 patients diagnosis was made after biopsy of suspicious lesion. In 18 patients definitive diagnosis was made according to results of imaging and clinical-laboratory results, while in three patients diagnosis was based on clinical and laboratory data (cancer related death or significant tumor marker increase). In patient-based analysis, the imaging study was defined as true-positive (TP) when at least one of suspected lesions was histopathologically confirmed to be malignant or responded to therapy. The ${ }^{18} \mathrm{~F}-\mathrm{FDG}$ PET/CT study without abnormal ${ }^{18} \mathrm{~F}-\mathrm{FDG}$ uptake and MRI studies without suspected lesions, if

Table 1. Demographic and clinical characteristics of patients included in the study $(\mathrm{N}=35)$

\begin{tabular}{llc}
\hline Gender & Male & 21 \\
& Female & 14 \\
\hline Age & Mean 60.6 & \\
& $<61$ & 15 \\
& $\geq 61$ & 20 \\
\hline Localization of primary tumor & Rectum & 13 \\
& Colon & 22 \\
\hline Chemo-radiotherapy & Yes & 31 \\
& No & 4 \\
\hline CEA & Normal & 20 \\
& Increased & 15 \\
\hline CA 19-9 & Normal & 20 \\
& Increased & 15 \\
\hline MRI & Positive & 20 \\
& Negative & 15 \\
\hline${ }^{18}$ F-FDG PET/CT & Positive & 27 \\
& Negative & 8 \\
\hline Progression during follow-up & Yes & 16 \\
& No & 19 \\
\hline
\end{tabular}

CEA: Carcinoembryogenic antigen; CA 19-9: Carbohydrate antigen 19-9; MRI: Magnetic resonance imaging; ${ }^{18} \mathrm{~F}-\mathrm{FDG}$ PET/CT: Fluorine-18-fluorodeoxyglucose positron emission tomography/computed tomography remained so during first six months, were considered as truenegatives (TN). A false-positive (FP) imaging study showed at least one lesion characterized as malignant, but without evidence of disease in first six months. Finally, false-negative (FN) studies had evidence of recurrence on further examination during the first six months despite negative imaging studies at first. In lesion-based analysis all detected lesions by different imaging modalities were compared to reference examination (histopathology or imaging) during first six months after PET/ CT and were separately defined as TP, TN, FP or FN.

Progression of the disease was considered in cases of detection of new lesions during follow-up; increase of the existing lesions in size and/or in metabolic activity in any imaging modality; significant increase of tumor marker levels and/ or in cases of disease-related death. The date of progression was noted and thus, the progression-free survival time was calculated from the day of PET/CT scan.

Statistical analysis. The sensitivity, specificity, positive predictive value (PPV), negative predictive value (NPV) and diagnostic accuracy of ${ }^{18} \mathrm{~F}$-FDG PET/CT, MRI and tumor markers in detection of recurrent CRC were calculated. The sensitivity of ${ }^{18} \mathrm{~F}$-FDG PET/CT and MRI was determined in lesion-based analysis. Cox proportional hazards regression model was used to determine whether various demographic and clinical factors, such as age ( $\leq 61$ vs $>61$ ), gender (male vs female), CEA and CA 19-9 levels (normal vs increased), MRI results (positive vs negative), ${ }^{18} \mathrm{~F}-\mathrm{FGD}$ PET/CT results (positive vs negative), and treatment changes based on PET/CT results (yes vs no) were associated with the higher risk of progression of the disease during follow-up. These analyses consisted of determination of hazard ratios (HR) for all factors with $95 \%$ confidence interval (CI). Survival analyses were performed using Kaplan-Meier method, and the groups were compared using the Log-rank test. A P value of less than 0.05 was considered significant.

\section{Results}

The demographic and clinical characteristics of patients included in the study are given in Table 1. 
Patient-based analysis. ${ }^{18} \mathrm{~F}-\mathrm{FDG}$ PET/CT was positive in $27 / 35$ patients, suggesting recurrent disease, with two patients with false-positive findings. Local recurrence was suggested in 12 patients (Figure 1A), liver metastases in 13 cases (Figure1B), and extra-hepatic disease (lung, peritoneum, bone) in $12 \mathrm{pa}-$ tients (Table 2.). In six out of eight cases with negative PET/ CT the presence of disease was not confirmed in follow-up (true-negatives). There were two patients with false-negative findings. Overall, the sensitivity, specificity, positive and negative predictive value and accuracy of ${ }^{18} \mathrm{~F}$-FDG PET/CT were $92.6 \%, 75 \%, 92.6 \%, 75 \%$ and $88.6 \%$, respectively.

MRI suggested recurrent disease in 20/35 patients, with 3 cases being false-positive. Local recurrence was observed in 7 patients, liver metastases in 12 cases, and supra-diaphragmal pulmonary metastasis in three patients. In $9 / 15$ patients with normal MRI findings, subsequent histopathological and/or imaging examination detected recurrence, suggesting these patients were false-negative. In patient-based analysis the sensitivity, specificity, positive and negative predictive value and accuracy of MRI in detection of recurrent colorectal cancer were $65.4 \%, 66.7 \%, 85 \%, 40 \%$ and $65.7 \%$, respectively.

CA 19-9 was elevated in $15 / 35$ patients, with values ranging from 39 to $660 \mathrm{U} / \mathrm{ml}$, while in 20 patients CA 19-9 values were within reference levels. In regard to imaging tests, among patients with abnormal MRI (20 patients), CA 19-9 was elevated in 9, and normal in 11 patients. CA 19-9 was elevated in $12 / 27$ patients with positive ${ }^{18} \mathrm{~F}$-FDG PET/CT scan. The sensitivity, specificity, PPV, NPV and accuracy of CA 19-9 in detection of recurrent colorectal cancer were $48.1 \%, 75 \%$, $86.7 \%, 30 \%$ and $54.3 \%$, respectively.

In addition, abnormal values of CEA were also recorded in $15 / 35$ patients, ranging from 5.1 to $711 \mathrm{ng} / \mathrm{ml}$. CEA was elevated in 9/20 patients with abnormal MRI scan, and in 13/27 patients with pathological PET/CT results. The sensitivity, specificity, PPV, NPV and accuracy of CEA in detection of recurrent colorectal cancer were $44.4 \%, 62.5 \%, 80 \%, 33.3 \%$ and $48.6 \%$, respectively.

Lesion-based analysis. The total number of lesions detected by ${ }^{18} \mathrm{~F}-\mathrm{FDG}$ PET/CT was higher compared to MRI. PET/CT identified 84 sites of intensive FDG uptake with suspicion of recurrence, out of which 19 were not confirmed during follow-up (false-positives). However, 14 new sites of recurrent disease were subsequently detected, and these were considered as PET false-negative lesions. Overall, the sensitivity of ${ }^{18} \mathrm{~F}-\mathrm{FDG}$ PET/CT in lesion-based analysis was $83.1 \%$. MRI detected 53 lesions, overall, out of which 45 lesions were confirmed in follow-up (true-positives). The sensitivity of MRI in lesion-based analysis was $68.2 \%$.

Ten patients were upstaged according to ${ }^{18} \mathrm{~F}$-FDG PET/ CT result, out of whom 8 patients were upstaged from no disease to stage I/II (4 patients) or stage IV (4 patients). In two patients PET scan showed distant metastases in addition to local recidive, while in 3 cases extra-hepatic disease was identified on PET, in addition to liver metastatic disease seen on MRI. In 3 patients local recidive was observed on PET, be-
Table 2. ${ }^{18} \mathrm{~F}-\mathrm{FDG}$ PET/CT results

\begin{tabular}{ll}
\hline Result & $\mathrm{n}$ \\
\hline Negative & 8 \\
Local recurrence & 7 \\
Local recurrence + liver & 3 \\
Local recurrence + extra-hepatic disease & 2 \\
Liver & 5 \\
Liver + extra-hepatic disease & 5 \\
Extra-hepatic disease & 5 \\
\hline
\end{tabular}

side known liver metastases. Two patients were down-staged, because although MRI suggested liver disease in one patient and local recurrence in another, ${ }^{18} \mathrm{~F}-\mathrm{FDG}$ PET/CT scan was negative. Overall, ${ }^{18} \mathrm{~F}-\mathrm{FDG}$ PET/CT changed the stage of disease in $12 / 35$ patients.

${ }^{18} \mathrm{~F}$-FDG PET/CT and treatment changes. In 7 cases surgical treatment and/or chemo-radiation was applied according to PET findings. In three cases, however, the presence of disseminated disease seen on PET/CT prevented unnecessary and futile surgical treatment. In one patient the planned surgical treatment was altered, with the widening of surgical field since PET detected new lesions in the liver. Finally, in two patients the metastatectomy of liver metastases was accompanied with chemotherapy, because PET/CT detected extra-hepatic disease. In 3 cases treatment was not changed, despite discordance in MRI and PET results. Overall, ${ }^{18} \mathrm{~F}-\mathrm{FDG}$ PET/CT induced therapy alterations in 13/35 (37.1\%) patients.

Progression-free survival. Progression of the disease was observed in 16/35 patients during follow-up. In 12 patients, progression was observed on imaging follow-up, with the clinical data suggesting progression in four of these patients (increase of tumor markers). In three patients progression was considered because of cancer-related death, while in one patient progression was considered due to significant increase of tumor markers. Possible factors associated with disease progression are presented in Tables 3 and 4. These factors

Table 3. Factors influencing possible progression of the disease during follow-up (Univariate Cox proportional hazardous model)

\begin{tabular}{lccc}
\hline & \multicolumn{3}{c}{ Univariate Cox regression } \\
\hline Variable & HR & $95 \%$ CI & $\mathrm{p}$ \\
\hline Age & 0.94 & $0.35-2.53$ & 0.907 \\
Gender & 2.95 & $0.94-9.18$ & 0.063 \\
CEA & 1.34 & $0.50-3.58$ & 0.558 \\
CA 19-9 & 2.56 & $0.95-6.90$ & 0.063 \\
MRI & 1.61 & $0.56-4.65$ & 0.376 \\
${ }^{18}$ F-FDG PET/CT & 4.81 & $0.64-36.52$ & 0.128 \\
Treatment change & 0.30 & $0.09-1.06$ & 0.062 \\
\hline
\end{tabular}

CEA: Carcinoembryogenic antigen; CA 19-9: Carbohydrate antigen 19-9; MRI: Magnetic resonance imaging; ${ }^{18} \mathrm{~F}$-FDG PET/CT: Fluorine-18-fluorodeoxyglucose positron emission tomography/computed tomography 
A

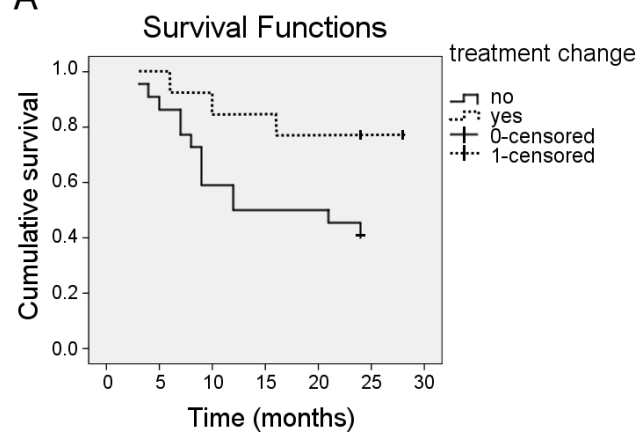

B

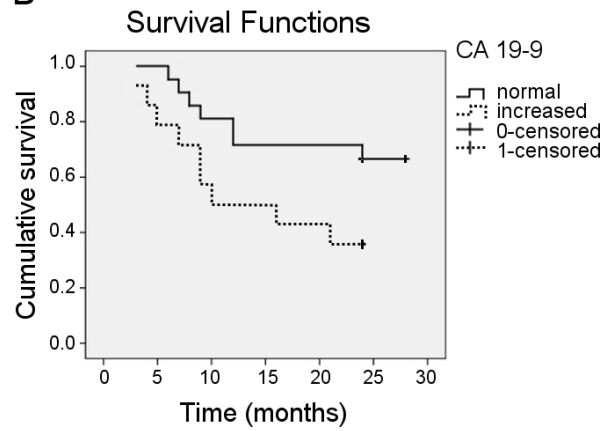

Figure 2. (A) Kaplan-Meier analysis of progression-free survival in patients with the change of planned treatment based on 18F-FDG PET/CT results compared to those without treatment changes (Log-rank test; $\mathrm{p}=0.046$ ); (B) Kaplan-Meier analysis of progression-free survival between patients with normal and elevated CA 19-9 levels (Log-rank test; $p=0.051$ )

were included in univariate and multivariate Cox regression analysis.

Univariate Cox regression analysis revealed that there was higher risk of progression in patients with increased CA 19-9 levels, as well as in male patients, with lower risk of progression in patients in whom PET/CT influenced on treatment changes, but without statistical significance $(p=0.063, p=0.063$ and $\mathrm{p}=0.062$, respectively).

However, when all possible influencing factors were included in multivariate analysis, risk of progression was significantly higher in patients with elevated CA 19-9 levels (HR 4.81; CI95\% $1.54-15.01 ; \mathrm{p}=0.007)$, as well as in male patients (HR 6.02; CI95\% 1.41 - 25.76; p=0.016). Moreover, the risk of diseases progression became significantly lower for those with treatment changes after PET/CT scan (HR 0.15; CI95\% $0.03-0.71 ; \mathrm{p}=0.017)$.

Median progression-free survival times in patients with and without treatment alterations after PET/CT scan were 24 and 16.5 months, respectively. Kaplan-Meier analysis, using Log rank test, showed significantly longer progression-free survival time in patients who had treatment plan changed

Table 4. Factors influencing possible progression of the disease during follow-up (Multivariate Cox proportional hazardous model)

\begin{tabular}{lccc}
\hline & \multicolumn{3}{c}{ Multivariate Cox regression } \\
\hline Variable & HR & $95 \% \mathrm{CI}$ & $\mathrm{p}$ \\
\hline Age & 1.50 & $0.43-5.26$ & 0.528 \\
Gender & 6.02 & $1.41-25.76$ & $0.016^{*}$ \\
CEA & 1.14 & $0.33-3.90$ & 0.834 \\
CA 19-9 & 4.81 & $1.54-15.01$ & $0.007^{*}$ \\
MRI & 0.91 & $0.23-3.52$ & 0.889 \\
${ }^{18}$ F-FDG PET/CT & 6.71 & $0.72-62.63$ & 0.095 \\
Treatment change & 0.15 & $0.03-0.71$ & $0.017^{*}$ \\
\hline
\end{tabular}

CEA: Carcinoembryogenic antigen; CA 19-9: Carbohydrate antigen 19-9; MRI: Magnetic resonance imaging; ${ }^{18} \mathrm{~F}-\mathrm{FDG}$ PET/CT: Fluorine-18-fluorodeoxyglucose positron emission tomography/computed tomography ${ }^{*} \mathrm{p}<0.05$ based on PET/CT compared to those in whom treatment was not changed $(\mathrm{p}=0.046)$ (Figure $2 \mathrm{~A})$.

Progression-free survival was worse in patients with elevated CA 19-9 levels, but this difference did not reach statistical significance (Kaplan-Meier, Log rank test; $\mathrm{p}=0.051$ ) (Figure 2B).

\section{Discussion}

This study showed higher accuracy and sensitivity of ${ }^{18} \mathrm{~F}$ FDG PET/CT in detection of recurrent colorectal cancer, compared to MRI, with much better diagnostic performance compared to CEA and CA 19-9. The significant impact of ${ }^{18} \mathrm{~F}-\mathrm{FDG}$ PET/CT based treatment changes and CA 19-9 levels on prognosis of our colorectal cancer patients was noticed.

The diagnostic strength of ${ }^{18} \mathrm{~F}-\mathrm{FDG}$ PET/CT in detection of recurrent colorectal cancer was proven through number of studies $[11,12]$. Contrary to authors suggesting higher specificity of PET in visualization of CRC recurrence [13], our results showed higher sensitivity of this imaging modality (92.6\% vs $75 \%)$, with only two false-negative studies. In these two patients presence of disease was confirmed despite negative PET/CT scan: in one patient significant increase of tumor markers was noted on first follow-up visit and in another patient metastasis in illiac bone was seen on first follow-up MRI. Also, there were two false positive cases of local recidive and liver metastases, later histopathologically proved to be benign.

The suggested follow-up of patients after resection with curative intent includes serial CT of chest, abdomen and pelvis, as well as regular serum CEA measurements [4]. In addition, intraluminal recurrences can be detected with recto/ colonoscopy. However, in large number of cases detection of extra-luminal recurrence and differentiation of postoperative changes from recurrence can be made by imaging tests, with MRI being method of choice by some authors [14], while others stress the role of PET/CT, especially in detection of lymph node metastases [15]. 
When metastases to the liver are suspected, ${ }^{18} \mathrm{~F}-\mathrm{FDG}$ PET/CT and MRI are methods most frequently employed in further treatment decision. Whether ${ }^{18} \mathrm{~F}-\mathrm{FDG}$ PET/CT, which can detect more easily extra-hepatic dissemination, or MRI, which can accurately characterize liver lesions, will be employed depends on various factors (e.g. cost, availability) [4].

In lesion-based analyses, our results also showed higher sensitivity of ${ }^{18} \mathrm{~F}-\mathrm{FDG}$ PET/CT compared to MRI (83.1\% vs 68.2\%). This in contrast with other studies [12], although some authors suggest better sensitivity of combined use of PET and contrast-enhanced CT [16]. Most of the lesions observed on PET scan in our study patients were confirmed as recurrence. Nineteen lesions suggested on PET were falsepositive (three loco-regional lesions, 5 liver lesions, and 11 suspected lymph nodes), while 14 lesions were missed on PET overall, out of which 8 lesions were in liver, three in lung, one in adrenal gland, one in abdominal lymph node and one in illiac bone. Although, MRI observed lower number of lesions overall compared to ${ }^{18} \mathrm{~F}$-FDG PET (53 vs 84 ), including falsepositive lesions ( $8 \mathrm{vs} 19$ ), there was larger number of missed lesions ( 21 vs 14). It should be noted that in MRI lesion-based analysis we did not take in account lesions in upper lung and mediastinum, identified on PET in four patients. However, this finding did not influence final result, since there were already present distant metastases, so stage of the disease as well as planned treatment were not changed in these patients. Recent study by Oh et al [17] showed equal sensitivity of PET and gadoxetic acid - enhanced liver MRI in detection of large liver lesions $(>2 \mathrm{~cm})$, and significantly higher sensitivity of MRI in detection small lesions $(<2 \mathrm{~cm})$. However, lesion size was not included in calculation of sensitivity in our study, and the number of lesions in the liver missed on PET and MRI was comparable (9 vs 10).

Serial measurements of CEA present inevitable surveillance tool in patients after resection of colorectal cancer. Although the sensitivity was proven in number of studies, it largely depends of threshold values, suggesting better sensitivity with lower cut-off values [18]. In our study, with referent values of $5.0 \mathrm{ng} / \mathrm{ml}$ for smokers, and $3.5 \mathrm{ng} / \mathrm{ml}$ for non-smokers, CEA showed moderate sensitivity in detection of recurrence. CEA level was increased in around 50\% (13/27) of our patients with PET positive findings, which not completely concurred with published results [19]. In addition, CA 19-9 showed low sensitivity (just below 50\%), which is in keeping with results of other studies performed on large cohorts [20].

Although the decision on further treatment of our patients was made based on different factors, imaging tests had the most powerful impact. After comparing the treatment plan before and after the ${ }^{18} \mathrm{~F}$-FDG PET/CT scan, we came to conclusion that the management was altered in $13 / 35$ patients. This complies with other publications [12], with the most of the changes being the consequence of detection of disseminated, extra-hepatic disease, which is known to be the advantage of PET scan.
The main objective of hybrid imaging in oncology is more precise and early detection, as well as accurate staging of active disease, in order to optimize the therapy and prolong survival. It has been shown that PET has the most significant impact in the change of preoperative management of rectal cancer [21]. In addition, surveillance of colorectal cancer patients with more than one PET/CT scan leads to the initiation of new treatment in approximately $35 \%$ and the change in previous management in 30\% [22]. This study also underlined longer survival in patients with all negative PET scans. In comparison with above mentioned, our results showed similar impact of PET/CT scan on treatment alterations (37.1\%).

Prognostic significance of preoperative ${ }^{18} \mathrm{~F}$-FDG PET/CT is well known and established through number of studies, and has more often been the objective of investigation compared to postoperative PET scans. It has been shown that pretreatment SUV and $\triangle$ SUV after preoperative treatment represent significant predictors of progression-free and overall survival in patients with locally advanced rectal tumors, as well as in patients with liver metastases $[23,24]$. The value of postoperative ${ }^{18} \mathrm{~F}$-FDG PET/CT in prognosis of survival has not been fully examined and understood. In our study, the detection of recurrence on PET/CT did not influence the prognosis. However, treatment changes induced by PET result significantly improved the prognosis, correlating with lower incidence of progression and longer progression-free survival time in these patients.

Another factor showing significant prognostic ability in our analysis was postoperative level of CA 19-9. Although its role as marker of recurrence was not impressive, the elevated value of CA 19-9 was important predictor of higher risk of progression during postoperative surveillance in our study. The similar results were observed by Abe et al [25], showing that combined elevation of CEA and CA 19-9 was significant predictor of recurrence and shorter recurrence-free survival, while normal CA 19-9 was independent predictor of longer overall survival. Normal CA 19-9 level in time of PET/CT scan was associated with longer survival in our patients, but this correlation did not reach significance. Postoperative levels of CEA and CA 19-9 may serve as indicators of when to perform $\mathrm{PET} / \mathrm{CT}$, which was proved in retrospective analysis by Wasserberg et al [26], but still needed prospective confirmation.

To our knowledge this is the first study addressing the prognostic significance of postoperative ${ }^{18} \mathrm{~F}-\mathrm{FDG}$ PET/CT, MRI and CEA and CA 19-9 levels in patients with recurrent colorectal cancer. However, our study has some limitations. The main drawback of this prospective study was small number of patients, as well as the fact that histopathological verification was not achieved in all suspected lesions, but confirmed through clinical and imaging follow-up. The follow-up period was not long enough to enable evaluation of overall survival in our patients. However, the prognostic significance regarding disease progression was determined. In addition, our study population was not balanced in gender, with higher prevalence of male patients, so results should be 
interpreted accordingly. This investigation will continue and include more patients, in order to evaluate the impact and prognostic significance of imaging and biochemical tests in long-term progression-free and overall survival.

In conclusion, the results of our study suggest higher accuracy and sensitivity of ${ }^{18} \mathrm{~F}-\mathrm{FDG}$ PET/CT, in both patientbased and lesion-based analysis, in detection of recurrent colorectal cancer, compared to MRI, with comparable specificity between these two imaging modalities. Although results of ${ }^{18} \mathrm{~F}$-FDG PET/CT scan did not predict the prognosis of our patients, treatment changes induced by this imaging method significantly improved prognosis and prolonged the progression-free survival, necessitating the need of PET/CT examination in determination of treatment in patients with recurrent colorectal cancer. In addition, despite CEA and CA 19-9 showed lower diagnostic performance in detection of recurrence, compared to imaging tools, elevated values of CA 19-9 in time of PET/CT scan were significantly associated with worse prognosis, indicating its value in postoperative surveillance.

Acknowledgements: The study is supported by the Serbian Ministry of Education and Science (Grant number 175018).

\section{References}

[1] SIEGEL R, DESANTIS C, JEMAL A. Colorectal cancer statistics, 2014. CA Cancer J Clin 2014; 64: 104-117. https://doi. org/10.3322/caac. 21220

[2] AMERICAN CANCER SOCIETY. Colorectal Cancer Facts \& Figures 2014-2016. Atlanta, Georgia: American Cancer Society, 2014. https://www.cancer.org/content/dam/cancer-org/ research/cancer-facts-and-statistics/colorectal-cancer-factsand-figures/colorectal-cancer-facts-and-figures-2014-2016. pdf, as accessed on June 23, 2017

[3] DESANTIS CE, LIN CC, MARIOTTO AB, SIEGEL RL, STEIN KD et al. Cancer treatment and survivorship statistics. CA Cancer J Clin 2014; 64: 252-271. https://doi.org/10.3322/ caac. 21235

[4] NATIONAL INSTITUTE FOR HEALTH AND CLINICAL EXCELLENCE. The Diagnosis and Management of Colorectal Carcinoma-Clinical Guideline CG131. NICE 2011; 1-185. https://www.nice.org.uk/guidance/cg131/documents/ colorectal-cancer-full-guideline2, as accessed on June 23, 2017

[5] KIM HS, LEE MR. Diagnostic accuracy of elevated serum carcinoembryonic antigen for recurrence in postoperative stage II colorectal cancer patients: comparison with stage III. Ann Coloproctol 2013; 29: 155-159. https://doi.org/10.3393/ ac.2013.29.4.155

[6] OZAWA T, ISHIHARA S, KAWAI K, NOZAWA H, YAMAGUCHI H et al. Prognostic significance of preoperative serum carbohydrate antigen 19-9 in patients with stage IV colorectal cancer. Clin Colorectal Cancer 2016; 15: e157-e163. https:// doi.org/10.1016/j.clcc.2016.04.012

[7] LU YY, CHEN JH, DING HJ, CHIEN CR, LIN WY et al. A systematic review and meta-analysis of pretherapeutic lymph node staging of colorectal cancer by 18 -FDG-PET or PET/ CT. Nucl Med Commun 2012; 33: 1127-1133. https://doi. org/10.1097/MNM.0b013e328357b2d9

[8] WAHL RL, JACENE H, KASAMON Y, LODGE MA. From RECIST to PERCIST: Evolving considerations for PET response criteria in solid tumors. J Nucl Med 2009; 50 Suppl 1:122S-150S. https://doi.org/10.2967/jnumed.108.057307

[9] KARANTANIS D, ALLEN-AUERBACH M, CZERNIN J. Sources and resources for oncologists to help answer the question: Is PET/CT appropriate for my patient? Hell J Nucl Med 2012; 15: 2-8.

[10] BYSTROM P, BERGLUND A, GARSKE U, H. JACOBSSON, A. SUNDIN et al. Early prediction of response to first-line chemotherapy by sequential [18F]-2-fluoro-deoxy-D-glucose positron emission tomography in patients with advanced colorectal cancer. Ann Oncol 2009; 20: 1057-1061. https:// doi.org/10.1093/annonc/mdn744

[11] YU T, MENG N, CHI D, ZHAO Y, WANG K et al. Diagnostic value of $18 \mathrm{~F}-\mathrm{FDG}$ PET/CT in detecting local recurrent colorectal cancer: a pooled analysis of 26 individual studies. Cell Biochem Biophys 2015; 72: 443-451. https://doi.org/10.1007/ s12013-014-0485-4

[12] MAFFIONE AM, LOPCI E, BLUEMEL C, GIAMMARILE F, HERRMANN K et al. Diagnostic accuracy and impact on management of 18F-FDG PET and PET/CT in colorectal liver metastasis: a meta-analysis and systenatic review. Eur J Nucl Med Mol Imaging 2015; 42: 152-163. https://doi.org/10.1007/ s00259-014-2930-4

[13] GADE M, KUBIK M, FISKER RV, THORLACIUS-USSING O, PETERSEN LJ. Diagnostic value of 18F-FDG PET/CT as first choice in the detection of recurrent colorectal cancer due to rising CEA. Cancer Imaging 2015; 15: 11. https://doi. org/10.1186/s40644-015-0048-y

[14] JHAVERI KS, HOSSEINI-NIK H. MRI of rectal cancer: an overview and update on recent advances. AJR Am J Roentgenol 2015; 205: w42-w55. https://doi.org/10.2214/AJR.14.14201

[15] SCHMIDT GP, BAUR-MELNYK A, HAUG A, UTZSCHNEIDER S, BECKER CR et al. Whole-body MRI at $1.5 \mathrm{~T}$ and 3T compared with FDG-PET-CT for the detection of tumour recurrence in patients with colorectal cancer. Eur Radiol 2009; 19: 1366-1378. doi: 10.1007/s00330-008-1289-

[16] JIMENEZ LONDONO GA, GARCIA VICENTE AM, SANCHEZ PEREZ V, ARAGON FJ, MARTIN AL et al. 18FFDG PET/contrast enhanced CT in the standard surveillance og high risk colorectal cancer patients. Eur J Rad 2014; 83: 2224-2230. https://doi.org/10.1016/j.ejrad.2014.08.016

[17] OH JW, OH SN, CHOI JI, CHOI MH, YOO IR et al. Does the gadoxetic acid-enhanced liver MRI impact on the treatment of patients with colorectal cancer? Comparison study with 18FFDG PET/CT. Biomed Res Int 2016; 2016: 8412071. https:// doi.org/10.1155/2016/8412071

[18] NICHOLSON BD, SHINKINS B, MANT D. Blood measurement of carcinoembryonic antigen level for detecting recurrence of colorectal cancer. JAMA 2016; 316:1310-1311. https://doi.org/10.1001/jama.2016.11212

[19] HUANG YY, LEE PI, LIU MC, CHEN CC, HUANG KC et al. A general cutoff level combined with personalized dynamic 
change of serum carcinoembryonic antigen can suggest timely use of FDG PET for early detection of recurrent colorectal cancer. Clin Nucl Med 2015; 40: e465-e469. https://doi. org/10.1097/RLU.0000000000000900

[20] OKAMURA R, HASEGAWA S, HIDA K, HOSHINO N, KAWADA K et al. The role of periodic serum CA 19-9 test in surveillance after colorectal cancer surgery. Int J Clin Oncol 2017; 22: 96-101. https://doi.org/10.1007/s10147-016-1027$\underline{4}$

[21] SCHNEIDER DA, AKHURST TJ, NGAN SY, WARRIER SK, MICHAEL $M$ et al. Relative value of restaging MRI, CT and FDG PET scan after preoperative chemoradiation for rectal cancer. Dis Colon Rectum 2016; 59: 179-186. https://doi. org/10.1097/DCR.0000000000000557

[22] MARCUS C, MARASHDEH W, AHN SJ, TAGHIPOUR M, SUBRAMANIAM RM. 18F-FDG PET/CT and colorectal cancer: value of fourth and subsequent posttherapy follow-up scans for patient management. J Nucl Med 2015; 56: 989-994. https://doi.org/10.2967/jnumed.115.156240
[23] KRUG B, CROTT R, DE CANNIERE L, D‘HONDT L, VANDER BORGHT T. A systematic review of the predictive value of F-18-fluoro-2-deoxyglucose positron emission tomography on survival in locally advanced rectal cancer after neoadjuvant chemoradiation. Colorectal Dis 2013; 15: e627-e633. https:// doi.org/10.1111/codi.12295

[24] XIA Q, LIU J, WU C, SONG S, TONG L et al. Prognostic significance of $18 \mathrm{~F}-\mathrm{FDG}$ PET/CT in colorectal cancer patients with liver metastases: a meta-analysis. Cancer Imaging 2015; 15:19. https://doi.org/10.1186/s40644-015-0055-Z

[25] ABE S, KAWAI K, ISHIHARA S, NOZAWA H, HATA K et al. Prognostic impact of carcinoembryonic antigen and carbohydrate antigen 19-9 in stage IV colorectal cancer patients after R0 resection. J Surg Res 2016; 205: 384-392. https://doi. org/10.1016/j.jss.2016.06.078

[26] WASSERBERG N, PURIM O, BARD V, KUNDEL Y, GORDON N et al. Early postoperative 18F-FDG PET/CT in high-risk stage III colorectal cancer. Clin Nucl Med 2015; 40: e222-e227. https://doi.org/10.1097/RLU.0000000000000692 


\title{
Distribution of the most common polymorphisms in TYMS gene in Slavic population of central Europe
}

\author{
A. PASTORAKOVA*, D. CHANDOGOVA, J. CHANDOGA, J. LUHA, D. BOHMER, J. MALOVA, T. BRAXATORISOVA, M. JUHOSOVA, S. REZNAKOVA, \\ R. PETROVIC \\ Comenius University in Bratislava, Faculty of Medicine, Institute of Medical Biology, Genetics and Clinical Genetics, Sasinkova 4, Bratislava 811 08, \\ Slovakia \\ ${ }^{*}$ Correspondence: andrea.pastorakova@fmed.uniba.sk
}

Received April 7, 2017/ Accepted July 19, 2017

\begin{abstract}
Thymidylate synthetase (TS) plays a critical role in the de novo synthesis of dTMP inside the cell. Therefore, TS is a suitable target for cytotoxic drugs such as fluoropyrimidines. Drug efficacy and toxicity depend on the intracellular level of TS, which is significantly influenced by the polymorphisms in the 5'UTR (TSER - rs45445694, TSER 3 G >C - rs2853542) and 3'UTR (1494del TTAAAG - rs151264360) of TYMS gene. Polymorphic variants of TYMS gene affect TS activity via gene expression and transcript stability. Patients who undergo fluoropyrimidine therapy may benefit from genetic testing prior to the administration of chemotherapy. At the 5 ' terminus of TYMS, there is a polymorphic region represented by a variable number of $28 \mathrm{bp}$ long tandem repeats (2-9 tandems) with the $\mathrm{G}$ or $\mathrm{C}$ nucleotide variant (SNP G>C). The 3'end of TYMS gene may decrease the stability of mRNA in the case of 6 base deletion (1494del6, D). In our study, we have focused on testing of TYMS gene polymorphisms, determination of TYMS variant frequencies in Western Slavic population and comparison of Slovak population with other populations.

We performed identification of 5'UTR (rs45445694 - TSER ${ }^{\star} 2$ or TSER ${ }^{\star} 3$; rs $2853542-\mathrm{TSER}^{\star} 3 \mathrm{G}>\mathrm{C}$; TSER ${ }^{\star 3}+$ ins 6 ) and 3’UTR (rs151264360/1494del6/D) polymorphic regions of TYMS gene among 96 volunteers by PCR-RFLP and fragment analysis. Slovak frequencies of selected polymorphisms were established as follows: the frequency of TSER ${ }^{\star}$, TSER 3 , TSER $^{\star} 3 \mathrm{G}>\mathrm{C}, 1494 \mathrm{del} 6 / \mathrm{D}$ and I to be $41 \%, 59 \%, 34 \%, 37.5 \%$ and $62.5 \%$ respectively. The high resolution of the capillary electrophoresis technique allowed among TSER ${ }^{\star} 3$ group identification of a subgroup of four individuals with rare 6bp insertion in $3 \mathrm{R}$ allele, id est $2.1 \%$ TSER ${ }^{\star} 3+$ ins 6 allele frequency. In our study, we have revealed individuals with rare $\mathrm{G}>\mathrm{C}$ substitution in the first $28 \mathrm{bp}$ tandem repeat of TSER ${ }^{\star}$ promoter enhancer region (rs183205964) as well, the overall frequency of this polymorphic allele in Slovak population was $2.1 \%$.

Our results proved that Slovak population is in Hardy-Weinberg equilibrium and proportion of TYMS polymorphisms is in accordance with other published data.
\end{abstract}

Key words: fluoropyrimidines, thymidylate synthetase, pharmacogenetics, polymorphism, Slovak

Fluoropyrimidine drugs such as 5-fluorouracil (5-FU) and the prodrugs represented by capecitabine and tegafur are extensively used in cancer therapy. The fluoropyrimidine treatment efficiency depends on the intracellular level of the enzyme thymidylate synthetase (TS). If TS is inhibited by fluoropyrimidines, the production of dTMP in the cell is blocked, which leads to the misincorporation of 5-FU metabolites into RNA and DNA, and finally to cell-cycle arrest and apoptosis [1]. Thymidylate synthetase protein is coded by TYMS gene consisting of 7 exons located on chromosome 18 (18p11.32). The therapy outcome and also toxicity are influenced by TS cellular content which depends on the interpatient genetic variability [2].

Expression and stability of thymidylate synthetase vary according to the polymorphisms in the variable number of 28-bp tandem repeats and SNP (single nucleotide polymorphism) in the 5'-untranslated region (UTR) and also depend on 6-bp insertion/deletion polymorphism in the 3'UTR of TYMS gene (Fig. 1). TYMS promoter enhancer region (TSER) contains the variable number of $28 \mathrm{bp}$ tandem repeats (CCGCGCCACTTGGCCTGCCTCCGTCCCG) which are repeated from 2 up to 9 times (rs45445694 for- 


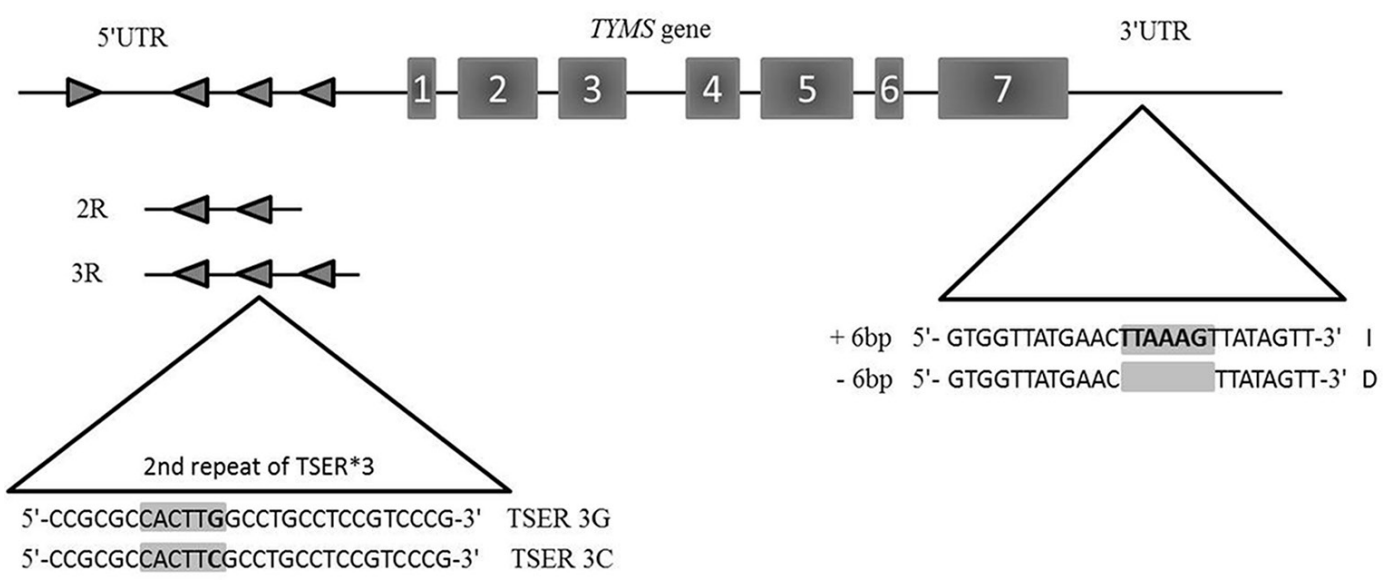

Figure 1. Structure of TYMS gene and 5'UTR and 3'UTR polymorphisms. TSER - Thymidylate Synthetase Enhancer Region, R - 28bp tandem repeat, I - I allele and D - D allele.

merly described as rs34743033), more prevalent as duplet $\left(2 \mathrm{R}, \mathrm{TSER}{ }^{\star}\right)$ or triplet $\left(3 \mathrm{R}, \mathrm{TSER}{ }^{\star} 3\right)$ [3]. Increased number of repeats raises TYMS RNA concentration and protein synthesis [3-6]. Every repeat contains E-box (enhancer box) binding site for upstream stimulatory factors (USF-1/USF2) functional only when guanine $(G)$ at the last position of CACTTG sequence is present. Both $2 \mathrm{R}$ and $3 \mathrm{R}$ wild-type alleles contain a cytosine in the last repeat which abolished the USF binding site in the repeat [7]. A clinical association has been found between reduced toxicity and drug efficacy in case of the $3 \mathrm{R} / 3 \mathrm{R}$ genotype, contrary patients with the $2 \mathrm{R} / 2 \mathrm{R}$ genotype showed an increased risk of toxicity, an increased response to fluoropyrimidine chemotherapy, and an increased survival time compared to individuals with the $2 \mathrm{R} / 3 \mathrm{R}$ or $3 \mathrm{R} / 3 \mathrm{R}$ genotype. The frequency of TSER ${ }^{*} 3(3 \mathrm{R})$ in the world is in the range from 50 to $60 \%$ except for Asian populations where the prevalence of TSER ${ }^{\star} 3$ is significantly higher (over 80\%) [3, 8, 9].

The SNP G>C substitution in the 12th nucleotide in the second repeat of TSER ${ }^{*} 3$ (rs2853542) alters TYMS expression by abolishing a transcription factor binding site $[7,10]$. Patients with TSER ${ }^{\star} 3 \mathrm{G}>\mathrm{C}\left(\mathrm{TSER}^{\star} 3 \mathrm{C}, 3 \mathrm{C}\right)$ polymorphism have a greater risk of toxicity due to the reduction in TYMS expression [10]. The TSER ${ }^{\star} 3$ patient might be stratified into high and low TYMS expression groups according to the presence of the $\mathrm{TSER}^{\star} 3 \mathrm{G}>\mathrm{C}$ polymorphism.

Decreased mRNA stability in vitro and lower gene expression in vivo was revealed by Mandola et al. [11] in association with the 3'UTR 6bp deletion allele located 447bp downstream of the TYMS transcription stop codon (rs151264360 formerly described as rs34489327 or rs16430; 1494del6, D) (Fig. 1). Frequency of variant with 6bp deletion in Caucasians is $26-29 \%$, $50 \%$ in Africans, and up to $76 \%$ in Asians $[11,12]$.

Other genetic and clinical factors may be also taken into account that may affect patient's risk for toxicity, survival time and therapy response.
The aim of this study was to analyse TYMS variants in Slovak population for the first time, to determine the frequency of polymorphisms in TYMS gene and to compare our findings with other populations. This study provides valuable information about the genetic variability of TYMS gene in Western Slavic population, hitherto missing.

\section{Materials and methods}

Samples of healthy unrelated volunteers were analysed by PCR, RFLP and fragment analysis (capillary electrophoresis) to estimate polymorphism frequencies in Slovak population. The analysed group consisted of 96 generally healthy individuals of Caucasian origin, randomly selected from the database of volunteers available at the Institute of Medical Biology, Genetics and Clinical Genetics, participants signed a written informed consent before participation in this study. Acquired data were checked for Hardy-Weinberg equilibrium and genetic linkage between variations.

DNA isolation. Blood samples for DNA extraction were collected in $3 \mathrm{ml}$ tubes containing potassium EDTA. Whole blood DNA was extracted from $200 \mathrm{ml}$ uncoagulated blood using Purification DNA Kit (DNA NucleoSpin Blood Kit; Macherey-Nagel, Düren, Germany).

Allele analysis. The 5'UTR VNTR (variable number of tandem repeats) region and 3'UTR region were amplified by PCR, the primers and PCR conditions used were previously described by Kawakami et al. [5] and by Ulrich et al. [12] were optimized for our laboratory settings. Primers for 5'UTR region (polymorphisms 2R/TSER ${ }^{\star} 2,3 \mathrm{R} / \mathrm{TSER}^{\star} 3$ - rs45445694; TSER $^{\star} 3+$ ins6) amplification primers and conditions as follow: 5'-[6FAM] GCGGAAGGGGTCCTGCCA-3' and 5'-TCCGAGCCGGCCACAGGCAT-3', PCR Master Mix (Thermo Fisher Scientific, Massachusetts, USA), PCR conditions: 5 min at $95{ }^{\circ} \mathrm{C}$; 30 cycles: $15 \mathrm{sec}$ at $95 \mathrm{C}, 30 \mathrm{sec}$ at $68^{\circ} \mathrm{C}, 30 \mathrm{sec}$ at $72^{\circ} \mathrm{C} ; 5$ min at $72{ }^{\circ} \mathrm{C}$. 
For 3'UTR region (1494del6/TYMSdel/D,I - rs151264360) amplification primers and condition as follow: 5'-[HEX] CAAATCTGAGGGAGCTGAGT-3'and 5'-CAGATAAGTGGCAGTACAGA-3, PCR Master Mix (Thermo Fisher Scientific, Massachusetts, USA), PCR conditions: $5 \mathrm{~min}$ at $95^{\circ} \mathrm{C}$; 30 cycles: $15 \mathrm{sec}$ at $95^{\circ} \mathrm{C}, 30 \mathrm{sec}$ at $60^{\circ} \mathrm{C}, 30 \mathrm{sec}$ at $72^{\circ} \mathrm{C}$; $5 \mathrm{~min}$ at $72^{\circ} \mathrm{C}$.

PCR products of 5'UTR and 3'UTR region were analysed with the ABI Prism 310 Genetic Analyzer (Applied Biosystems, USA) (Figure 2).

SNP analysis (PCR-RFLP). SNP of G or C in $2 \mathrm{R}$ and $3 \mathrm{R}$ allele ( $\mathrm{G}>\mathrm{C}$ substitution) [13]: VNTR PCR products were digested 16 hours at $37^{\circ} \mathrm{C}$ with HaeIII (New England Biolabs, Massachusetts, USA). Detection of the SNP was performed after electrophoresis (Origins 2100U, Elchrom Scientific, Switzerland) in Spreadex EL 300 Wide Mini S-2x13 or Spreadex EL 300 Wide Mini S-2x25 and staining with GelRed Nucleic Acid Gel Stain (Biotium, California, USA). Briefly, SNP detection: for 3G (3R-GGC) - fragments: 31bp - 28bp - 66bp - 10bp; 3C (3R-GCC): $31 b p-94 b p-10 b p ; 2 G C(w t$
2R allele): $31 b p-66 b p-10 b p ; 2 G G: 31 b p-28 b p-38 b p$ - 10bp; 2CG (2R-CG): 59bp - 38bp - 10bp; 2CC (2R-CC): 97bp - 10bp (Figure 3).

PCR-RFLP was used to confirm results of $3^{\prime}$ UTR region fragment analysis using PCR product digestion with DraI (New England Biolabs, Massachusetts, USA), D allele $-142 \mathrm{bp}$ fragment, I allele - 60bp and 88bp fragment (Figure 3) [12].

Statistic methods. Chi-square test was used to confirm or rule out whether the Slovak population is in accordance with Hardy-Weinberg equilibrium (Table 1,2).

Fisher's exact test of contingency tables was applied to detect significant differences in frequency of alleles in Slovak and other population. If the $\mathrm{P}$-value of appropriate test is $\mathrm{P}<0.05$; the corresponding distributions are significantly different at the 5\% significance level. In the tables, significantly different P-values are marked bold (Table 3).

Sample power test was used to analyse the strength of Fisher's exact test for significantly different results of allele distribution (Table 3).

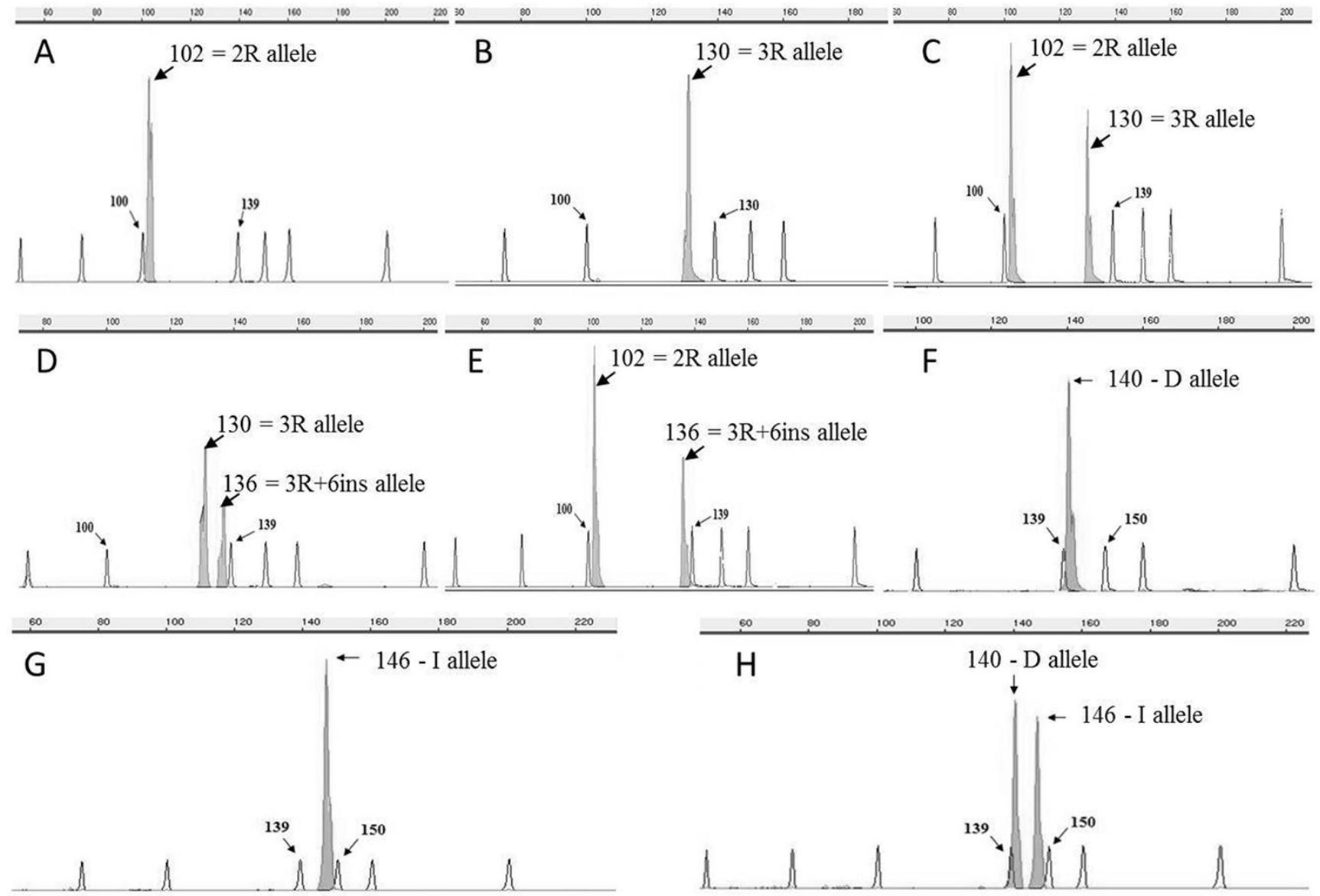

Figure 2. Fragment analysis of 5'UTR TSER region (2R, 3R, 3R+ins6) and 3'UTR region (D and I alleles) of TYMS gene. A) 2R/2R homozygote represented by fragment 102bp, B) $3 R / 3 R$ homozygote - 130bp fragment, C) $2 R / 3 R$ heterozygote $-102 \mathrm{bp} / 130 \mathrm{bp}, \mathrm{D}) 3 \mathrm{R} / 3 \mathrm{R}+\mathrm{ins} 6 \mathrm{heterozygote}-130 \mathrm{bp} / 136 \mathrm{bp}, \mathrm{E}$ ) $2 \mathrm{R} / 3 \mathrm{R}$ +ins6 heterozygote $-102 \mathrm{bp} / 136 \mathrm{bp}$. The nearest size standard peaks 100 and $139 \mathrm{bp} . \mathrm{F}) \mathrm{D} / \mathrm{D}$ homozygote represented by fragment $140 \mathrm{bp}, \mathrm{G}) \mathrm{I} / \mathrm{I}$ homozygote - 146bp fragment, H) D/I heterozygote - 140bp/146bp. The nearest size standard peaks 139 and $150 \mathrm{bp}$. 


\section{Results}

We have genotyped 96 Slovak DNA samples of healthy volunteers and determined frequencies of TYMS polymorphisms in Slovak population for the first time. Using fragment analysis of the 5'UTR VNTR TYMS region, we have identified five different genotypes and the following frequencies: TSER ${ }^{\star} 2$ / TSER ${ }^{\star} 2$ homozygotes represented by $20.8 \%$, TSER $* 3 / \mathrm{TSER}^{\star} 3$ homozygotes with $35.4 \%$ portion, $\mathrm{TSER}^{\star} 2 / \mathrm{TSER}^{\star} 3$ heterozygotes with $39.6 \%$ ratio, $\mathrm{TSER}^{\star} 3 / \mathrm{TSER}^{\star} 3+\mathrm{ins} 6$ with $3.1 \%$ and $\operatorname{TSER}^{\star} 2 / \mathrm{TSER}^{\star} 3+$ ins 6 with $1.1 \%$ (Table 1 ). The overall frequency of TSER ${ }^{\star} 3$ (with TSER ${ }^{\star} 3+$ ins6) prevalent allele was $59 \%$, the TSER ${ }^{\star} 2$ portion was $41 \%$ (Table 3 ). Within the TSER ${ }^{\star} 3$ allele, we have distinguished TSER ${ }^{\star} 3$ allele with $6 \mathrm{bp}$ insertion (TSER ${ }^{\star} 3+$ ins6) with $2.1 \%$ portion (Table 1 ). Based on the Chi-square test the distribution of the allelic variants
Table 1. Genotypes and allele frequencies of 5'UTR TSER region polymorphism (2R, 3R, 3R+ins6) and 3'UTR region polymorphism (D and I) in Slovak population.

\begin{tabular}{lcccc}
\hline Genotype & Number & $\begin{array}{c}\text { Frequency } \\
(\%)\end{array}$ & Allele & $\begin{array}{c}\text { Frequency } \\
(\%)\end{array}$ \\
\hline 2R/3R & 38 & 39.6 & $3 \mathrm{R}$ & 56.8 \\
3R/3R & 34 & 35.4 & $2 \mathrm{R}$ & 41.1 \\
2R/2R & 20 & 20.8 & 3R+ins6 & 2.1 \\
3R/3R+ins6 & 3 & 3.1 & & \\
2R/3R+ins6 & 1 & 1.1 & & \\
& & & & \\
D/I & 50 & 52.1 & $\mathrm{I}$ & 62.5 \\
I/I & 35 & 36.5 & $\mathrm{D}$ & 37.5 \\
D/D & 11 & 11.4 & & \\
\hline
\end{tabular}

Chi-square test confirmed the Hardy-Weinberg equilibrium in Slovak population (5'UTR TSER $\mathrm{P}=0.740$, 3'UTR polymorphisms $\mathrm{P}=0.553$ ).

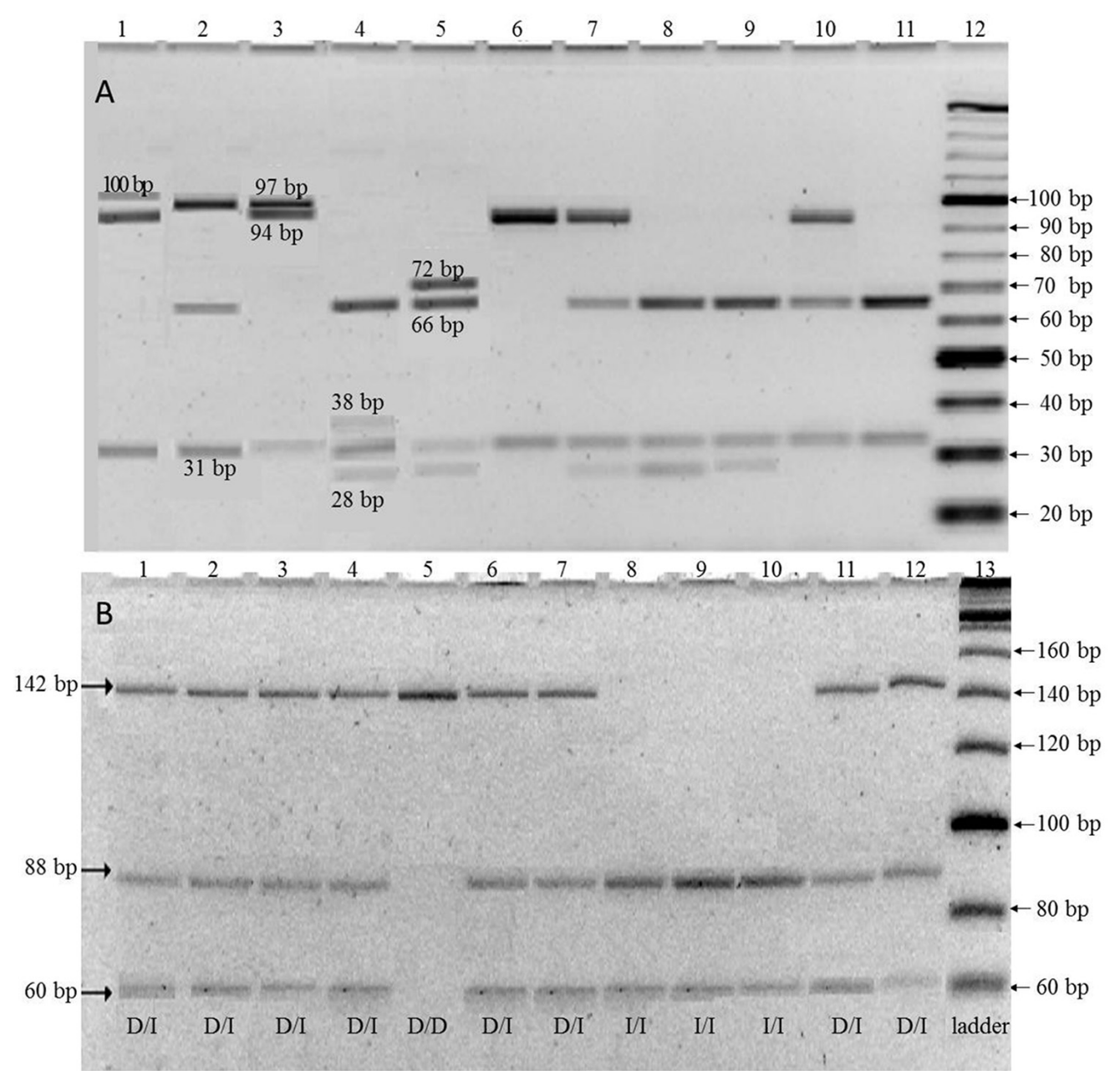

Figure 3. PCR-RFLP A) of 5'UTR region fragment analysis using HaeIII digestion of PCR products (sample, genotype, fragments). 1 - 3C/3C+ins6 $100 \mathrm{bp}$ and $94 \mathrm{bp}$ fragments; $2-2 \mathrm{CC} / 2 \mathrm{GC}-97 \mathrm{bp}$ and $66 \mathrm{bp}, 3-2 \mathrm{CC} / 3 \mathrm{C}-97 \mathrm{bp}$ and $94 \mathrm{bp}, 4-2 \mathrm{GG} / 2 \mathrm{GC}-38 \mathrm{bp}, 66 \mathrm{bp}$ and $28 \mathrm{bp}, 5-2 \mathrm{GC} / 3 \mathrm{G}+\mathrm{ins} 6-72 \mathrm{bp}$, 66bp and 28bp, $6-3 \mathrm{C} / 3 \mathrm{C}-94 \mathrm{bp} ; 7-3 \mathrm{C} / 3 \mathrm{G}-94 \mathrm{bp}, 66 \mathrm{bp}$ and $28 \mathrm{bp} ; 8-3 \mathrm{G} / 3 \mathrm{G}-66 \mathrm{bp}$ and $28 \mathrm{bp} ; 9-2 \mathrm{GC} / 3 \mathrm{G}-66 \mathrm{bp}$ and $28 \mathrm{bp} ; 10-2 \mathrm{GC} / 3 \mathrm{C}-94 \mathrm{bp}$ and 66bp; 11 - 2GC/2GC - 66bp, 12 - DNA ladder. B) of 3'UTR region fragment analysis using DraI digestion of PCR product. D allele -142bp fragment, I allele - 60bp and 88bp fragment. PCR-RFLP confirmed results of fragment analysis of all 96 samples. Sample genotypes: 1, 2, 3, 4, 6, 7, 11, 12 - D/I heterozygote; 5 - D/D homozygote; 8, 9, 10 - I/I homozygote; 13 - DNA ladder. 
Table 2. Distribution of SNP (G>C substitution) genotypes and alleles of TYMS in Slovak population.

\begin{tabular}{lcccc}
\hline Genotype & Number & $\begin{array}{c}\text { Frequency } \\
(\%)\end{array}$ & Allele & $\begin{array}{c}\text { Frequency } \\
(\%)\end{array}$ \\
\hline 2GC/3C & 23 & 24 & $2 \mathrm{GC}$ & 38.5 \\
$3 \mathrm{C} / 3 \mathrm{G}$ & 21 & 21.9 & $3 \mathrm{C}$ & 32.8 \\
$2 \mathrm{GC} / 2 \mathrm{GC}$ & 17 & 17.7 & $3 \mathrm{G}$ & 24.0 \\
$2 \mathrm{GC} / 3 \mathrm{G}$ & 13 & 13.5 & $2 \mathrm{CC}$ & 2.1 \\
$3 \mathrm{C} / 3 \mathrm{C}$ & 7 & 7.3 & $3 \mathrm{C}+$ ins 6 & 1.6 \\
$3 \mathrm{G} / 3 \mathrm{G}$ & 6 & 6.3 & $2 \mathrm{GG}$ & 0.5 \\
$3 \mathrm{C} / 3 \mathrm{C}+$ ins6 & 3 & 3.1 & $3 \mathrm{G}+$ ins6 & 0.5 \\
2CC/2GC & 2 & 2.1 & & \\
2CC/3C & 2 & 2.1 & & \\
2GC/2GG & 1 & 1 & & \\
2GC/3G+ins6 & 1 & 1 & & \\
\hline
\end{tabular}

Chi-square test confirmed the Hardy-Weinberg equilibrium in Slovak population $(\mathrm{P}=0.999)$.

of TYMS in Slovak population (Table 1) is in Hardy-Weinberg equilibrium. The detection of the TSER ${ }^{\star} 3+$ ins 6 allele was probably not within the detection limit in the studies with which we compared our population. Therefore, when comparing the frequencies of different populations, we have merged the frequency of TSER $* 3+$ ins 6 allele with TSER ${ }^{\star} 3$ allele frequency. The frequencies of investigated polymorphisms correlate with data previously reported for Caucasians. Based on the calculated P-value the significant difference was found in frequency of $2 \mathrm{R}$ and $3 \mathrm{R}$ polymorphic allele (rs45445694) between Chinese, Kenyan, Ghanaian populations comparing to Slovak population, while the proportion of TSER ${ }^{\star}$ and TSER $^{\star} 3$ was similar in the rest of the analysed populations (Macedonia, African-Americans, American and British Caucasians, Southwest Asian, and Spain) (Table 3). The sample power for comparative analysis of Slovak and: the population of Kenya (0.95), the population of Ghana (0.93) and Chinese population (0.999) is strong.

We have used PCR-RFLP analysis to confirm the distribution of genotypes and allele among Slovaks and to subdivide groups into detailed categories according to the content of $\mathrm{G}$ or $\mathrm{C}$ within the twelfth nucleotide of the $28 \mathrm{bp}$ repeats of TSER $^{\star} 2$, TSER $^{\star} 3$ or TSER $* 3+$ ins6 (Table 2). Frequency of wild-type TSER ${ }^{\star}$ allele (2GC) was $38.5 \%$, 3C allele (without $3 \mathrm{C}+$ ins6) $32.8 \%$, $3 \mathrm{G}$ allele (without $3 \mathrm{G}+$ ins6) $24 \%$; we have also come across rare alleles, such as the 2CC allele with $2.1 \%$ frequency, $3 \mathrm{C}+$ ins 6 allele with $1.6 \%$ portion, $2 \mathrm{GG}$ allele $0.5 \%$ and $3 \mathrm{G}+$ ins6 $0.5 \%$. Based on the Chi-square test, the distribution of TSER ${ }^{\star} 2(2 \mathrm{GC}, 2 \mathrm{CC}, 2 \mathrm{GG}), \mathrm{TSER}^{\star} 3 \mathrm{G}$, TSER $^{\star} 3 \mathrm{C}$ allelic variants of TYMS in Slovak population is in Hardy-Weinberg equilibrium (Table 2). In order to compare our population with other studies, we merged Slovak 2GC, $2 \mathrm{CC}$ and $2 \mathrm{GG}$ frequencies to TSER ${ }^{\star}$ frequency $(41 \%)$ as well as the $3 \mathrm{C}+$ ins 6 frequency with $3 \mathrm{C}$ frequency $(34 \%)$ and also the $3 \mathrm{G}+\mathrm{ins} 6$ frequency with $3 \mathrm{G}(25 \%)$. In addition to this, the detailed investigation of SNP G or C variants in TSER ${ }^{*}$ (rs2853542) revealed a significant difference between Slovaks and African-Americans, and between Slovak and Chinese populations as well (Table 3 ). The sample power for comparative analysis of Slovak and African Americans (0.96), as well as Chinese population (1), is strong.

In our work, the polymorphism rs151264360 in the 3'UTR region of TYMS (1494del6/TYMSdel/D, I) was analysed by fragment analysis and the results were confirmed using PCRRFLP with $62.5 \%$ presence of I allele and $37.5 \%$ of D allele. The proportion of genotypes was as follows: more than half (52.1\%) D/I heterozygotes, 36.5\% I/I homozygotes, $11.4 \%$ $\mathrm{D} / \mathrm{D}$ homozygotes (Table 1). Distribution of $\mathrm{D}$ and I alleles is in Hardy-Weinberg equilibrium in Slovak population. Statistically significant difference in frequency of distribution of D and I alleles was found comparing Slovak and Spanish populations (Table 3). The sample power of Fisher's exact test comparing the population of Slovakia with the population of Spain is moderately strong (0.726).

In our study, we have analysed the distribution of combined genotypes of 5'UTR TSER region polymorphism (2R, 3R) and 3'UTR region polymorphism (D and I) in 37 volunteers ( $\mathrm{Ta}-$ ble 4). We have found 8 genotype combinations from possible genotypes and following frequencies: most prevalent genotype $3 \mathrm{R} / 3 \mathrm{R}-\mathrm{I} / \mathrm{D}$ with $24.4 \%$; then $2 \mathrm{R} / 3 \mathrm{R}-\mathrm{I} / \mathrm{D} 21.6 \% ; 2 \mathrm{R} / 2 \mathrm{R}-\mathrm{I} / \mathrm{I}$, $2 \mathrm{R} / 2 \mathrm{R}-\mathrm{I} / \mathrm{D}$ and $2 \mathrm{R} / 3 \mathrm{R}-\mathrm{I} / \mathrm{I}$ equally $10.8 \%$; $3 \mathrm{R} / 3 \mathrm{R}-\mathrm{I} / \mathrm{I}$ and $3 \mathrm{R} / 3 \mathrm{R}-\mathrm{D} / \mathrm{D}$ equally $8.1 \%$; and $2 \mathrm{R} 3 \mathrm{R}-\mathrm{D} / \mathrm{D} 5.4 \%$. We did not identify individuals with the genotype $2 R / 2 R-D / D$.

\section{Discussion}

TYMS gene genotyping is a way that can potentially help predict patient response to fluoropyrimidines prior to the use of chemotherapy, thus leading to better-personalized treatment. We have completed the genotype study of TYMS gene in Slovak population that shows the distribution of TYMS variants among Slovaks. Our study is unique not only because of the analysis of VNTR of TYMS gene but also because of $\mathrm{G}$ and $\mathrm{C}$ determination within the twelfth nucleotide of the $28 \mathrm{bp}$ repeat in every tandem. According to our knowledge, such analysis has been not published for any Western Slavic population yet. The TYMS allele frequencies in Slovaks are comparable with other published Caucasian populations. The most prevalent allele in our study was TSER ${ }^{\star} 3$ (3R) with $59 \%$ frequency, less frequent allele was TSER ${ }^{\star} 2$ allele with $41 \%$ portion, and we have also detected the rare 6-bp insertion in the TSER ${ }^{\star} 3$ allele (TSER ${ }^{*} 3+$ ins 6$)$ in the frequency of $2.1 \%$. The TSER* $3+$ ins 6 variant was firstly described by Thomas et al. with the frequency of $0.4 \%$ in Caucasians and $1.3 \%$ in African-Americans [13]. The functional effect of the 6-bp insertion in 5'UTR of the $3 \mathrm{R}$ allele remains to be determined. There were attempts to determine Western Slavic population, but the data are not detailed. In the study of Goricar and colleagues [14], the frequencies of two groups of genotypes for Slovenians are mentioned. The frequency for the first 
Table 3. Differences in frequency of 2R and 3R alleles; 2R, 3G and 3C alleles; $D$ and I alleles in Slovak and other populations analysed by Fisher's exact test of contingency tables.

\begin{tabular}{|c|c|c|c|c|c|c|c|}
\hline \multirow{2}{*}{ Population } & \multicolumn{4}{|c|}{ Allele frequency (\%) } & \multirow{2}{*}{ P-value } & \multirow{2}{*}{$\begin{array}{l}\text { Sample } \\
\text { power }\end{array}$} & \multirow{2}{*}{ Reference } \\
\hline & $2 \mathrm{R}$ & $3 R$ & $4 \mathrm{R}$ & 9R & & & \\
\hline Slovakia $(\mathrm{n}=192)$ & 41 & 59 & ND & $\mathrm{ND}$ & & & Current study \\
\hline Macedonia $(n=210)$ & 38 & 62 & ND & $\mathrm{ND}$ & 0.476 & NC & {$[16]$} \\
\hline Kenya $(n=196)$ & 44 & 49 & 7 & $\mathrm{ND}$ & 0.000 & 0.950 & {$[8]$} \\
\hline Ghana $(n=496)$ & 40 & 56 & 3 & 1 & 0.028 & 0.930 & [8] \\
\hline African-Americans $(\mathrm{n}=184)$ & 46 & 52 & 2 & $\mathrm{ND}$ & 0.062 & NC & [8] \\
\hline American Caucasians $(\mathrm{n}=208)$ & 46 & 54 & ND & $\mathrm{ND}$ & 0.364 & NC & [8] \\
\hline British Caucasians ( $\mathrm{n}=194)$ & 45 & 54 & 1 & $\mathrm{ND}$ & 0.295 & NC & {$[8]$} \\
\hline China $(n=192)$ & 18 & 82 & ND & $\mathrm{ND}$ & 0.000 & 0.999 & {$[17]$} \\
\hline Southwest Asian $(\mathrm{n}=190)$ & 38 & 62 & ND & $\mathrm{ND}$ & 0.532 & NC & [17] \\
\hline \multirow[t]{2}{*}{ Spain $(n=250)$} & 47 & 53 & ND & ND & 0.248 & NC & {$[34]$} \\
\hline & $2 \mathrm{R}$ & $3 G$ & $3 \mathrm{C}$ & other & & & \\
\hline Slovakia $(\mathrm{n}=192)$ & 41 & 25 & 34 & $\mathrm{ND}$ & & & Current study \\
\hline Macedonia $(\mathrm{n}=210)$ & 38 & 23 & 39 & $\mathrm{ND}$ & 0.570 & NC & [16] \\
\hline Spain $(n=240)$ & 47 & 23 & 30 & $\mathrm{ND}$ & 0.448 & NC & {$[34]$} \\
\hline White Ethnicity $(\mathrm{n}=198)$ & 41 & 26 & 33 & $\mathrm{ND}$ & 0.909 & NC & {$[10]$} \\
\hline Hispanic $(\mathrm{n}=196)$ & 42 & 30 & 26 & 2 & 0.062 & $\mathrm{NC}$ & {$[10]$} \\
\hline African Americans $(\mathrm{n}=118)$ & 48 & 37 & 15 & $\mathrm{ND}$ & 0.001 & 0.960 & {$[10]$} \\
\hline \multirow[t]{2}{*}{ China $(n=160)$} & 19 & 51 & 30 & ND & 0.000 & 1 & [10] \\
\hline & $\mathrm{D}$ & & I & & & & \\
\hline Slovakia $(\mathrm{n}=192)$ & 37 & & 63 & & & & Current study \\
\hline Caucasians $(\mathrm{n}=190)$ & 29 & & 71 & & 0.131 & NC & {$[12]$} \\
\hline Northern Ireland $(\mathrm{n}=888)$ & 32 & & 68 & & 0.150 & NC & {$[35]$} \\
\hline Spain $(n=256)$ & 26 & & 74 & & 0.013 & 0.726 & [34] \\
\hline
\end{tabular}

Significantly different P-value is marked bold, $\mathrm{n}=$ number of alleles, $\mathrm{ND}=$ not detected, $\mathrm{NC}=$ not calculated.

group of TSER ${ }^{\star} 2 /$ TSER $^{\star} 2$ homozygotes is $17.9 \%$ and for the other group, consisting of individuals with TSER ${ }^{\star} 2 / \mathrm{TSER}^{\star} 3$ and TSER ${ }^{\star} 3 /$ TSER $^{\star} 3$ genotypes, it is $82.1 \%$. Jakubowska et al. [15] published an analysis of Polish population for the genotype groups: $22 \%$ of TSER ${ }^{\star} 2 / \mathrm{TSER}^{\star} 2$ homozygotes, $30 \%$ of TSER ${ }^{\star} 3 / \mathrm{TSER}^{\star} 3$ homozygotes and $48 \%$ of heterozygotes consisting of individuals with TSER ${ }^{\star} 2 / \mathrm{TSER}^{\star} 3$ or TSER ${ }^{\star} 2$ / $\mathrm{TSER}^{\star} 4$ genotypes. Macedonian population, one of the South Slavs, has been studied by Kapedanovska and colleagues [16]. The distribution of Macedonian genotypes is as described: $12 \%$ TSER $^{\star} 2 / \mathrm{TSER}^{\star} 2$ homozygotes, $30 \% \mathrm{TSER}^{\star} 2 / \mathrm{TSER}^{\star} 3 \mathrm{C}$, $20 \% \mathrm{TSER}^{\star} 2 / \mathrm{TSER}^{\star} 3 \mathrm{G}, 19 \% \mathrm{TSER}^{\star} 3 \mathrm{C} / \mathrm{TSER}^{\star} 3 \mathrm{C}, 10 \%$ TSER $* 3 \mathrm{C} / \mathrm{TSER}^{\star} 3 \mathrm{G}$.

In our group of volunteers, we have not found individuals with 4 or more $28 \mathrm{bp}$ tandem repeats. We have found differences in the distribution of TSER polymorphic alleles between Slovak population comparing the populations of Kenya, Ghana, and China. According to the opinion of Marsh and colleagues [17], polymorphism of TSER in humans may be a by-product of migration rather than allele evolution; environmental and/or other epigenetic factors can shift the allele frequencies in different regional dietary variations. In selective pressure of low intake of thymidine individuals with higher thymidylate synthase, due to the multiplication of TSER tandem repeat have selective advantage. Zhang and colleagues [18] demonstrated that besides humans, TSER is length polymorphic in many nonhuman primates while monomorphic in others. They suggested that the most recent common ancestor of hominoids and Old World monkeys probably possessed triple repeats. But now triple and double repeats, via deletion of one repeat, are two dominant types in hominoids and Old Word monkeys.

Table 4. Distribution of combined genotypes of 5'UTR TSER region polymorphism (2R, 3R) and 3'UTR region polymorphism (D and I) in Slovak population.

\begin{tabular}{lcc}
\hline Genotype (N=37) & Number & Frequency (\%) \\
\hline 2R/2R, I/I & 4 & 10.8 \\
2R/2R, I/D & 4 & 10.8 \\
2R/2R, D/D & 0 & 0 \\
2R/3R, I/I & 4 & 10.8 \\
2R/3R, I/D & 8 & 21.6 \\
2R/3R, D/D & 2 & 5.4 \\
3R/3R, I/I & 3 & 8.1 \\
3R/3R, I/D & 9 & 24.4 \\
3R/3R, D/D & 3 & 8.1 \\
\hline
\end{tabular}

$\mathrm{N}=$ number of genotypes 
There have been numerous attempts to associate TSER polymorphisms with clinical outcomes in cancer patients receiving fluoropyrimidine therapy, conclusions have been inconsistent. Several studies have revealed links between TSER genotype and the response to chemotherapy, and mention that TSER ${ }^{\star} /$ TSER $^{\star} 2$ genotype or patients with at least one TSER ${ }^{2}$ allele have a better response to fluorouracil as compared to patients with TSER $* 3 / \mathrm{TSER}^{*} 3$ genotype $[4,19-22]$. In vitro studies have shown up to four times more efficient translation from a construct with three repeats compared with two repeats $[3,23]$. In the study of in vivo analysis of colorectal cancer tissues, no relation between genotype and transcription has been revealed, but TSER genotype was associated with TS protein expression. Specifically, cancer tissues with the $3 R / 3 R$ genotype had a significantly higher TS protein expression level than did those with the $2 \mathrm{R} / 3 \mathrm{R}$ genotype. Cancer tissue with $2 \mathrm{R} / 2 \mathrm{R}$ genotype had the lowest TS protein expression [23].

De Bock and colleagues [7] have analysed thymidylate synthase activity in vivo in patients with colorectal cancer according to TSER polymorphism by measurement of $2^{\prime}$-deoxyuridine (dUrd) plasma level, a surrogate marker of TS inhibition. Plasma levels of dUrd were significantly different between genotypes, but in contrast to others, not to the absolute number of functional repeated elements (USF E-box) [7]. This study suggests that not the number of functional sequences, but their position within the promoter determines TYMS gene activity [7].

Up to date, there are no prescription and genotyping recommendations of TYMS gene prior therapy. Accurate information about the activity of thymidylate synthase depending on TSER genotype is missing as well. There are several studies trying to find out TSER genotype-specific guidelines for fluoropyrimidines dosing. Haller et al. [24] demonstrated regional differences in the tolerability profiles of fluoropyrimidines in the retrospective study. More treatment-related toxicity was reported in the US patients compared with the rest of the world for bolus fluorouracil/leucovorin and capecitabine in first-line metastatic colorectal cancer and adjuvant colon cancer. In the adjuvant setting, a range of fluoropyrimidine tolerability was observed, with East Asian patients having the lowest, and US patients the highest [24]. Soo and colleagues [25] sought to develop TSER specific guideline for capecitabine dosing. In their phase I study, they revealed a possibility to escalate the capecitabine dose of TSER 3R/3R advanced and/or metastatic cancer patients from lower the FDA-approved dose (from $1250 \mathrm{mg} / \mathrm{m}^{2}$ to $1500 \mathrm{mg} / \mathrm{m}^{2}$ ) [25].

In accordance with previous studies, the significant inverse association between the 5-FU toxicity and number of $28 \mathrm{bp}$ tandem repeats in 5'UTR region of TYMS gene was reported by some authors $[4,26,27]$. In the Saif's case report, they have described the first case of severe takotsubo cardiomyopathy related to DPD deficiency (heterozygous for the c.85T $>\mathrm{C} \mathrm{mu-}$ tation) and homozygous polymorphism of TYMS (TSER ${ }^{\star} 2 /$ $\mathrm{TSER}^{\star} 2,2 \mathrm{R} / 2 \mathrm{R}$ ) in a patient with colon cancer following 5-FU containing regimen [28]. Despite controversy in the literature, overall TSER ${ }^{\star} 2 / \mathrm{TSER}^{\star} 2$ finding predicts improved survival of patients receiving 5 -FU chemotherapy but also increases the risk for 5-FU toxicity. Wang and colleagues have also observed pancytopenia and severe gastrointestinal toxicities in Caucasian TSER ${ }^{\star} 2 /$ TSER $^{\star} 2$ homozygous patient with squamous cell rectal cancer after initiated 5-FU therapy in combination with mitomycin- $\mathrm{C}$ and radiation therapy followed after surgical excision [29]. The G>C substitution within the 12th nucleotide of the second repeat of TSER ${ }^{\star} 3$ (rs2853542) alters the TYMS expression due to abolished USF-1 binding site [10]. Morganti et al. demonstrated the reduction in TYMS expression in the case of $\mathrm{G}>\mathrm{C}$ substitution in the second repeat of TSER ${ }^{\star} 3$ (TSER ${ }^{\star} 3 \mathrm{C}$ ) comparing to TSER ${ }^{\star} 3 \mathrm{G}$ homozygotes and other genotypes in the colonic mucosa of 48 colorectal cancer patients [30]. The frequency of TSER ${ }^{\star} 3 \mathrm{C}$ varies among world population from $15 \%$ in African Americans up to $33 \%$ in whites [10]. In Slovak population, TSER ${ }^{\star} 3 \mathrm{C}$ allele frequency was $34 \%$ including TSER $* 3 \mathrm{C}+\mathrm{ins} 6$ allele with frequency $1.6 \%$. Marcuello and colleagues showed an improved overall response in metastatic colorectal cancer patients receiving 5-fluorouracil with the low expression genotypes (patients without any TSER ${ }^{*} 3 \mathrm{G}$ alleles) [31]. This SNP may further stratify TSER ${ }^{*} 3$ individuals into high and low TYMS expression groups.

Another identified SNP with reduced effect on TS activity was analysed by Meulendijks and colleagues. They studied the $\mathrm{G}>\mathrm{C}$ substitution in the first $28 \mathrm{bp}$ tandem repeat of $2 \mathrm{R}$ promoter-enhancer region of TYMS (rs183205964 known as the $2 \mathrm{RC}$ allele) among 1605 patients of this 28 patients (1.7\%) carried the 2RC (our tag 2CC) allele. They observed significantly more frequent early severe toxicity and toxicity-related hospitalization in risk-associated genotype carriers (2RG/2RC, $3 \mathrm{RC} / 2 \mathrm{RC}$ and $2 \mathrm{RC} / 2 \mathrm{RC}$ ). There was only one patient with the rare genotype $2 \mathrm{RC} / 2 \mathrm{RC}$ in the study, who had to be hospitalized twice and had severe febrile neutropenia, diarrhoea, and hand-foot syndrome [32]. The G>C substitution in the first $28 \mathrm{bp}$ tandem repeat of promoter enhancer region of TYMS was firstly described by Lincz and colleagues in 2007 [33]. In our study, we have identified 2 individuals with genotype $2 \mathrm{RC} / 2 \mathrm{RG}$ (our tag $2 \mathrm{CC} / 2 \mathrm{GC}$ ) and 2 with $2 \mathrm{RC} / \mathrm{TSER}^{*} 3 \mathrm{C}$ (our tag 2CC/3C), the overall frequency of the rs183205964 polymorphic allele in Slovak population was $2.1 \%$.

On the other hand, Mandola et al. have measured TS mRNA amount in liver metastasis of 43 patients with advanced metastatic colorectal carcinoma and determined genotype - mRNA level correlation according to D and I allele presence. They found that patients with $\mathrm{D} / \mathrm{D}$ genotype had decreased intratumoral TS mRNA to approximately $24 \%$ of TS mRNA amount of intratumoral TS mRNA in individuals with I/I genotype, while TS expression of D/I heterozygotes fell between two extremes with roughly $48 \%$ [11].

The knowledge of patient genotype prior fluoropyrimidine may help therapists to adequately set up treatment and prevent undesirable complications and life-threatening conditions in the future, despite the fact that clear predictive strategy has 
not been developed for clinical use yet. Other comprehensive haplotype studies involving analysis of all aforementioned polymorphisms in a relationship with therapy effectiveness and the toxicity risks are necessary to achieve the prescription and genotyping recommendations of TYMS gene prior to therapy.

Acknowledgements: This study was supported by the grant from MZSR 2007/39-FNSPBA-04. For the English correction to MSc. Linda Vasilova, Institute of Foreign Languages, Faculty of Medicine, Comenius University in Bratislava, Slovakia.

\section{References}

[1] LONGLEY DB, HARKIN DP, JOHNSTON PG. 5-fluorouracil: mechanisms of action and clinical strategies. Nat Rev Cancer 2003; 3: 330-338. https://doi.org/10.1038/nrc1074

[2] MEULENDIJKS D, ROZEMAN EA, CATS A, SIKORSKA $\mathrm{K}$, JOERGER $\mathrm{M}$ et al. Pharmacogenetic variants associated with outcome in patients with advanced gastric cancer treated with fluoropyrimidine and platinum-based triplet combinations: a pooled analysis of three prospective studies. Pharmacogenomics J 2016. https://doi.org/10.1038/ tpj.2016.81

[3] HORIE N, AIBA H, OGURO K, HOJO H, TAKEISHI K. Functional analysis and DNA polymorphism of the tandemly repeated sequences in the 5 -terminal regulatory region of the human gene for thymidylate synthase. Cell Struct Funct 1995; 20: 191-197. https://doi.org/10.1247/csf.20.191

[4] PULLARKAT ST, STOEHLMACHER J, GHADERI V, XIONG YP, INGLES SA et al. Thymidylate synthase gene polymorphism determines response and toxicity of 5-FU chemotherapy. Pharmacogenomics J 2001; 1: 65-70. https:// doi.org/10.1038/sj.tpj.6500012

[5] KAWAKAMI K, OMURA K, KANEHIRA E, WATANABE Y. Polymorphic tandem repeats in the thymidylate synthase gene is associated with its protein expression in human gastrointestinal cancers. Anticancer Res 1999; 19: 3249-3252.

[6] ULRICH CM, BIGLER J, BOSTICK R, FOSDICK L, POTTER JD. Thymidylate synthase promoter polymorphism, interaction with folate intake, and risk of colorectal adenomas. Cancer Res 2002; 62: 3361-3364.

[7] DE BOCK CE, GARG MB, SCOTT N, SAKOFF JA, SCORGIE FE et al. Association of thymidylate synthase enhancer region polymorphisms with thymidylate synthase activity in vivo. Pharmacogenomics J 2011; 11: 307-314. https://doi. org/10.1038/tpj.2010.43

[8] MARSH S, AMEYAW MM, GITHANG'A J, INDALO A, OFORI-ADJEI D et al. Novel thymidylate synthase enhancer region alleles in African populations. Hum Mutat 2000; 16: 528. https://doi.org/10.1002/1098-1004(200012)16:6<528::AIDHUMU11>3.0.CO;2-W

[9] LUO HR, LU XM, YAO YG, HORIE N, TAKEISHI K et al. Length polymorphism of thymidylate synthase regulatory region in Chinese populations and evolution of the novel alleles. Biochem Genet 2002; 40: 41-51. https://doi. org/10.1023/A:1014589105977
[10] MANDOLA MV, STOEHLMACHER J, MULLER-WEEKS S, CESARONE G, YU MC et al. A novel single nucleotide polymorphism within the 5 ' tandem repeat polymorphism of the thymidylate synthase gene abolishes USF-1 binding and alters transcriptional activity. Cancer Res 2003; 63: 2898-2904.

[11] MANDOLA MV, STOEHLMACHER J, ZHANG W, GROSHEN S, YU MC et al. A 6 bp polymorphism in the thymidylate synthase gene causes message instability and is associated with decreased intratumoral TS mRNA levels. Pharmacogenetics 2004; 14: 319-327. https://doi. org/10.1097/00008571-200405000-00007

[12] ULRICH CM, BIGLER J, VELICER CM, GREENE EA, FARIN FM et al. Searching expressed sequence tag databases: discovery and confirmation of a common polymorphism in the thymidylate synthase gene. Cancer Epidemiol Biomarkers Prev 2000; 9: 1381-1385.

[13] THOMAS F, HOSKINS JM, DVORAK A, TAN BR, MCLEOD HL. Detection of the G>C SNP and rare mutations in the 28-bp repeat of TYMS using gel-based capillary electrophoresis. Pharmacogenomics 2010; 11: 1751-1756. https://doi. org/10.2217/pgs. 10.170

[14] GORICAR K, ERCULJ N, FAGANEL KOTNIK B, DEBELJAK $\mathrm{M}$, HOVNIK $\mathrm{T}$ et al. The association of folate pathway and DNA repair polymorphisms with susceptibility to childhood acute lymphoblastic leukemia. Gene 2015; 562: 203-209. https://doi.org/10.1016/j.gene.2015.02.077

[15] JAKUBOWSKA A, GRONWALD J, MENKISZAK J, GORSKI B, HUZARSKI T et al. BRCA1-associated breast and ovarian cancer risks in Poland: no association with commonly studied polymorphisms. Breast Cancer Res Treat 2010; 119: 201-211. https://doi.org/10.1007/s10549-009-0390-5

[16] KAPEDANOVSKA NESTOROVSKA A, JAKOVSKI K, NAUMOVSKA Z, HILJADNIKOVA BAJRO M, STERJEV $\mathrm{Z}$ et al. Distribution of the most Common Genetic Variants Associated with a Variable Drug Response in the Population of the Republic of Macedonia. Balkan J Med Genet 2015; 17: 5-14. https://doi.org/10.2478/bjmg-2014-0069

[17] MARSH S, COLLIE-DUGUID ES, LI T, LIU X, MCLEOD HL. Ethnic variation in the thymidylate synthase enhancer region polymorphism among Caucasian and Asian populations. Genomics 1999; 58: 310-312. https://doi.org/10.1006/ geno.1999.5833

[18] ZHANG YW, LUO HR, RYDER OA, ZHANG YP. Evolution of the tandem repeats in thymidylate synthase enhancer region (TSER) in primates. Gene 2004; 338:47-54. https://doi. org/10.1016/j.gene.2004.05.018

[19] IACOPETTA B1, GRIEU F, JOSEPH D, ELSALEH H. A polymorphism in the enhancer region of the thymidylate synthase promoter influences the survival of colorectal cancer patients treated with 5-fluorouracil. Br J Cancer 2001; 85: 827-830. https://doi.org/10.1054/bjoc.2001.2007

[20] KRAJINOVIC M, COSTEA I, CHIASSON S. Polymorphism of the thymidylate synthase gene and outcome of acute lymphoblastic leukaemia. Lancet 2002; 359: 1033-1034.

[21] VILLAFRANCA E, OKRUZHNOV Y, DOMINGUEZ MA, GARCÍA-FONCILLAS J, AZINOVIC I et al. Polymorphisms of the repeated sequences in the enhancer region of the 
thymidylate synthase gene promoter may predict downstaging after preoperative chemoradiation in rectal cancer. J Clin Oncol 2001; 19: 1779-1786. https://doi.org/10.1200/ LCO.2001.19.6.1779

[22] JOERGER M, HUITEMA AD, BOOT H, CATS A, DOODEMAN VD et al. Germline TYMS genotype is highly predictive in patients with metastatic gastrointestinal malignancies receiving capecitabine-based chemotherapy. Cancer Chemother Pharmacol 2015; 75: 763-772. https://doi.org/10.1007/ s00280-015-2698-7

[23] KAWAKAMI K, SALONGA D, PARK JM, DANENBERG $\mathrm{KD}$, UETAKE $\mathrm{H}$ et al. Different lengths of a polymorphic repeat sequence in the thymidylate synthase gene affect translational efficiency but not its gene expression. Clin Cancer Res 2001; 7: 4096-4101.

[24] HALLER DG, CASSIDY J, CLARKE SJ, CUNNINGHAM D, VAN CUTSEM E et al. Potential regional differences for the tolerability profiles of fluoropyrimidines. J Clin Oncol 2008; 26: 2118-2123. https://doi.org/10.1200/JCO.2007.15.2090

[25] SOO RA, SYN N, LEE SC, WANG L, LIM XY et al. Pharmacogenetics-Guided Phase I Study of Capecitabine on an Intermittent Schedule in Patients with Advanced or Metastatic Solid Tumours. Sci Rep 2016; 6: 27826. https://doi.org/10.1038/ srep27826

[26] LECOMTE T, FERRAZ JM, ZINZINDOHOUE F, LORIOT MA, TREGOUET DA et al. Thymidylate synthase gene polymorphism predicts toxicity in colorectal cancer patients receiving 5-fluorouracil-based chemotherapy. Clin Cancer Res 2004; 10: 5880-5888. https://doi.org/10.1158/1078-0432. CCR-04-0169

[27] ROSMARIN D, PALLES C, CHURCH D, DOMINGO E, JONES A et al. Genetic markers of toxicity from capecitabine and other fluorouracil-based regimens: investigation in the QUASAR2 study, systematic review, and meta-analysis. J Clin Oncol 2014; 32: 1031-1039. https://doi.org/10.1200/ LCO.2013.51.1857

[28] SAIF MW, SMITH M, MALONEY A. The First Case of Severe Takotsubo Cardiomyopathy Associated with 5-Fluorouracil in a Patient with Abnormalities of Both Dihydropyrimidine Dehydrogenase (DPYD) and Thymidylate Synthase (TYMS)
Genes. Cureus 2016; 8: e783. https://doi.org/10.7759/cu$\underline{\text { reus. } 783}$

[29] WANG B, WALSH SJ, SAIF MW. Pancytopenia and Severe Gastrointestinal Toxicities Associated with 5-Fluorouracil in a Patient with Thymidylate Synthase (TYMS) Polymorphism. Cureus 2016; 8: e798. https://doi.org/10.7759/cureus.798

[30] MORGANTI M, CIANTELLI M, GIGLIONI B, PUTIGNANO AL, NOBILI S et al. Relationships between promoter polymorphisms in the thymidylate synthase gene and mRNA levels in colorectal cancers. Eur J Cancer 2005; 41: 2176-83. https://doi.org/10.1016/j.ejca.2005.06.016

[31] MARCUELLO E, ALTES A, DEL RIO E, CESAR A, MENOYO A et al. Single nucleotide polymorphism in the 5 ' tandem repeat sequences of thymidylate synthase gene predicts for response to fluorouracil-based chemotherapy in advanced colorectal cancer patients. Int J Cancer 2004; 112: 733-737. https://doi. org/10.1002/ijc.20487

[32] MEULENDIJKS D, JACOBS BA, ALIEV A, PLUIM D, VAN WERKHOVEN $\mathrm{E}$ et al. Increased risk of severe fluoropyrimidine-associated toxicity in patients carrying a $\mathrm{G}$ to $\mathrm{C}$ substitution in the first 28-bp tandem repeat of the thymidylate synthase 2R allele. Int J Cancer 2016; 138: 245-253. https:// doi.org/10.1002/ijc.29694

[33] LINCZ LF, SCORGIE FE, GARG MB, ACKLAND SP. Identification of a novel single nucleotide polymorphism in the first tandem repeat sequence of the thymidylate synthase $2 \mathrm{R}$ allele. Int J Cancer 2007; 120: 1930-1934. https://doi.org/10.1002/ ijc. 22568

[34] DOTOR E, CUATRECASES M, MARTÍNEZ-INIESTA M, NAVARRO M, VILARDELL F et al. Tumor thymidylate synthase 1494del6 genotype as a prognostic factor in colorectal cancer patients receiving fluorouracil-based adjuvant treatment. J Clin Oncol 2006; 24: 1603-1611. https://doi. org/10.1200/JCO.2005.03.5253

[35] KEALEY C, BROWN KS, WOODSIDE JV, YOUNG I, MURRAY L et al. A common insertion/deletion polymorphism of the thymidylate synthase (TYMS) gene is a determinant of red blood cell folate and homocysteine concentrations. Hum Genet 2005; 116: 347-353. https://doi.org/10.1007/s00439$\underline{004-1243-2}$ 